\title{
Climate-induced storminess forces major increases in future storm surge hazard in the South China Sea region
}

\author{
Melissa Wood ${ }^{1}$, Ivan D. Haigh ${ }^{1}$, Le Quan Quan², Nguyen Nghia Hung ${ }^{2}$, Tran Ba Hoang ${ }^{2}$, Stephen E. Darby ${ }^{3}$, \\ ${ }^{1}$ School of Ocean and Earth Science, National Oceanography Centre Southampton, University of Southampton, \\ Waterfront Campus, European Way, Southampton, UK \\ ${ }^{2}$ Southern Institute of Water Resource Research (SIWRR), 658th Vo Van Kiet Avenue, Ward 1, District 5, Ho \\ Chi Minh city, Vietnam \\ ${ }^{3}$ School of Geography and Environmental Science, University of Southampton, Highfield, Southampton, UK \\ ${ }^{4}$ National Oceanography Centre Southampton, University of Southampton, UK \\ ${ }^{5}$ Tyndall Centre for Climate Change Research, University of East Anglia, Norwich, UK \\ ${ }^{6}$ Institute for Environmental Studies (IVM), Vrije Universiteit Amsterdam, 1081 HV, Amsterdam, The \\ 15 Netherlands
}

Correspondence to: Ivan Haigh (I.D.Haigh @ soton.ac.uk) 


\begin{abstract}
It is vital to robustly estimate the risks posed by extreme sea levels, especially in tropical regions where cyclones can generate large storm surges and observations are too limited in time and space to deliver reliable analyses. To address this limitation for the South China Sea region, we force a hydrodynamic model with a new synthetic database representing 10,000 years of past/present and future tropical cyclone activity, to investigate climate change impacts on extreme sea levels forced by storm surges ( \pm tides). We show that, as stronger and more numerous tropical cyclones likely pass through this region over the next 30 years, both the spatial extent and severity of storm surge hazard increases. While extreme storm surge events in this location become generally a more frequent occurrence in the future, larger storm surges around Vietnam and China coastlines are projected to regionally amplify this hazard. This threatens low-lying, densely-populated areas such as the Red and Mekong River deltas, while sections of the Cambodian and Thai coastline face previously unseen storm surge hazards.

30 These future hazards strongly signal that coastal flood management and adaptation in these areas should be reviewed for their resilience against future extreme sea levels.
\end{abstract}

\title{
1 Introduction
}

The warming of the Earth's seas as a result of anthropogenic climate change represents a pressing challenge to humanity. Because of projected sea-level rise, between $2.5 \%$ and $4.1 \%$ of the world's population is estimated to be at risk of 1\% Annual Exceedance Probability (AEP; 1:100 year) coastal flooding by 2100, under the mean SSP5-8.5 scenarios and assuming no coastal flood defences (Kirezci et al., 2020). This is an increase of 52\% compared to the coastal populations affected by this hazard today. The majority of this inland flooding is expected to be due to extreme sea levels arising from high tides, storm surges, and wave set-up, further exacerbated by projected rising mean sea levels. Nevertheless, in contrast to the large number of studies that have focused on changes in global mean sea-levels, much less research has been devoted to determining the contribution of climate-driven changes in storm activity in forcing extreme sea levels. There has been an assumption that storm surge statistics will not change significantly over the next century, that surge behaviour is stationary. As a result, our understanding of how tides, storm surges, and waves influence sea level extremes is only modestly understood (Fox-Kemper et al., 2021). As pointed out by Muis et al., (2016) and Dullaart et al. (2021), the influence of low probability tropical cyclone (TC) events in particular are often overlooked in global assessments of extreme sea level flooding.

The people most acutely at risk from these TC and storm surge induced extreme sea levels today are those living both within zones of intense TC activity and upon low-lying deltas (Dullaart et al., 2021; Edmonds et al., 2020; Kirezci et al., 2020; Woodruff et al., 2013; McGranahan et al., 2007). It is estimated that almost 230 million

50 people (3\% of the global population) are directly exposed to storm surge hazard derived from tropical and extratropical cyclones (SwissRe, 2017). Sadly, strong winds, storm surges and associated flooding from TCs have caused nearly three million deaths worldwide since 1700 (Nicholls, 2006), and they continue to cause devastation: just five major TCs this century have killed over 150,000 people (Cyclone Nargis in 2008 - Fritz et al., 2009; Hurricane Katrina in 2005 - Knabb et al., 2005; Hurricane Maria in 2017 - Santos-Burgoa et al., 2018 \& Pasch 
et al., 2018; Typhoon Haiyan in 2013 - WMO 2021 \& Lagmay et al., 2015; and Typhoon Bopha in 2012 - OCHA, 2013). It is anticipated that there will be substantial changes in the frequency and severity of TCs in the future, in particular in tropical and mid-latitude regions (Emanuel 2021; Fox-Kemper et al., 2021; Knutson et al., 2020; Wahl et al., 2017; Wong et al., 2014; Woodruff et al., 2013; Mousavi et al., 2011.).

Despite the gravity of the issue, the two most recent reports of the Intergovernmental Panel on Climate Change (IPCC) underscore that there is currently 'low confidence' in our ability to predict how storm surges may contribute to changes in future sea level extremes (Wong et al., 2014; Fox-Kemper et al., 2021). This deep uncertainty arises not only from the significant challenge of predicting changes in tropical and mid-latitude cyclone activity at a regional scale, but also because of the small number of storm surge studies available at the time of the last IPCC Assessment Review. A key challenge lies in the essential difficulty of capturing storm surge data associated with events that are, by their very nature, somewhat infrequent. TCs are rare events that typically affect comparatively short stretches of coastline $(<500 \mathrm{~km})$ as they approach land, and so they are underrepresented in the sparsely distributed network of global tide gauges (Bloemendaal et al., 2020; Pugh and Woodworth 2014). Furthermore, analysing extreme storm surge behaviour, and estimating storm surge hazard, ideally requires long (>100 years) temporal records, which do not exist in most tropical regions (Irish et al., 2011).

70 This limitation is acutely problematic because extreme sea level statistics based on short records are notoriously imprecise (Kirezci et al., 2020; Lin and Emanuel 2016; Irish et al., 2011).

To overcome this data insufficiency, past studies have adopted two variant approaches with the common goal of extending the historic sea level record available from existing tide gauges. The first approach is to reconstruct multi-decadal storm surge signals through the use of statistical models to infer surge time-series from more widely available meteorological datasets. This has been done at both regional and global scales, using, for example, the tide gauge record and $20^{\text {th }}$ Century Reanalysis data (Zhang and Wang 2021; Cid et al., 2017, 2018) or a mixture of climate reanalyses (Wahl and Chambers 2016; Tadesse and Wahl 2021). These methods use simple linear or multiple regression models on climate indices to reconstruct long time series of surge levels from which extreme values and trends can be more robustly estimated. Statistical approaches mostly benefit from modest

80 computational resource needs, but this advantage is traded-off against the use of meteorological forcings that often have insufficient spatial resolution in tropical regions to capture the effects of cyclone activity on sea levels.

The second approach involves the use of hydrodynamic models to create multi-decadal time-series of surge-driven extreme sea levels across gridded domains. TC induced storm surges are challenging to model at continental or global scales because these storms typically have sizes less than the model mesh resolution, or are smoothed out 85 in the large grid cells of meteorological datasets, and are therefore difficult to resolve (Kirezci et al., 2020; Bloemendaal et al., 2019b; Takagi et al., 2017; Larson et al., 2014; Murakami and Sugi 2010). An earlier version of the Global Tide and Surge Model (GTSM, Muis et al. 2016) using ERA-Interim data was found to underestimate TC induced extreme sea levels. This was overcome with model resolution improvements and use of ERA5 reanalysis climate data in the latest iteration, to successfully simulate past and present extreme sea levels 90 (C3S 2017; Muis et al. 2020).

To address the scarcity of adequate storm surge components within extreme sea level analysis, several studies have recently attempted to force numerical storm surge models with synthetic datasets that seek to represent longterm TC activity. For example, Haigh et al. (2014) extended the work of Harper et al., (2009) and generated a 
10,000 year synthetic dataset of TC activity for the Australian region. These atmospheric data were used to force

a MIKE 21 hydrodynamic of the Australian coastline to produce a 61-year hindcast of sea levels from which to estimate present day exceedance probabilities due to storm surge. Similarly, Vousdoukas et al., (2016) forced a Delft3D-Flow hydrodynamic model with 70 years of ERA-interim atmospheric reanalysis data to simulate storm surges around European coastlines, demonstrating that extreme storm surge levels will augment relative sea-level rise at some locations by over 30\% under SSP5-8.5 future pathway scenarios. Most recently Dullaart et al., (2021) coupled the GTSMv3 model with a statistically significant number of generated synthetic TC track data to produce past/present (1980-2018) storm tides and sea level return period estimates for global coastlines, directly confronting the problems of precision in relative location (of tide gauge) and availability of storm data. This synthetic TC track data was obtained from the work of Bloemendaal et al., (2020) who developed Synthetic TC geneRation Model (STORM). STORM statistically resamples and simulates TC tracks and intensities from 38 years of historical atmospheric data from the International Best Track Archive for Climate Stewardship dataset (IBTrACS; Knapp et al., 2010) to the equivalent of 10,000 years under the same climate conditions.

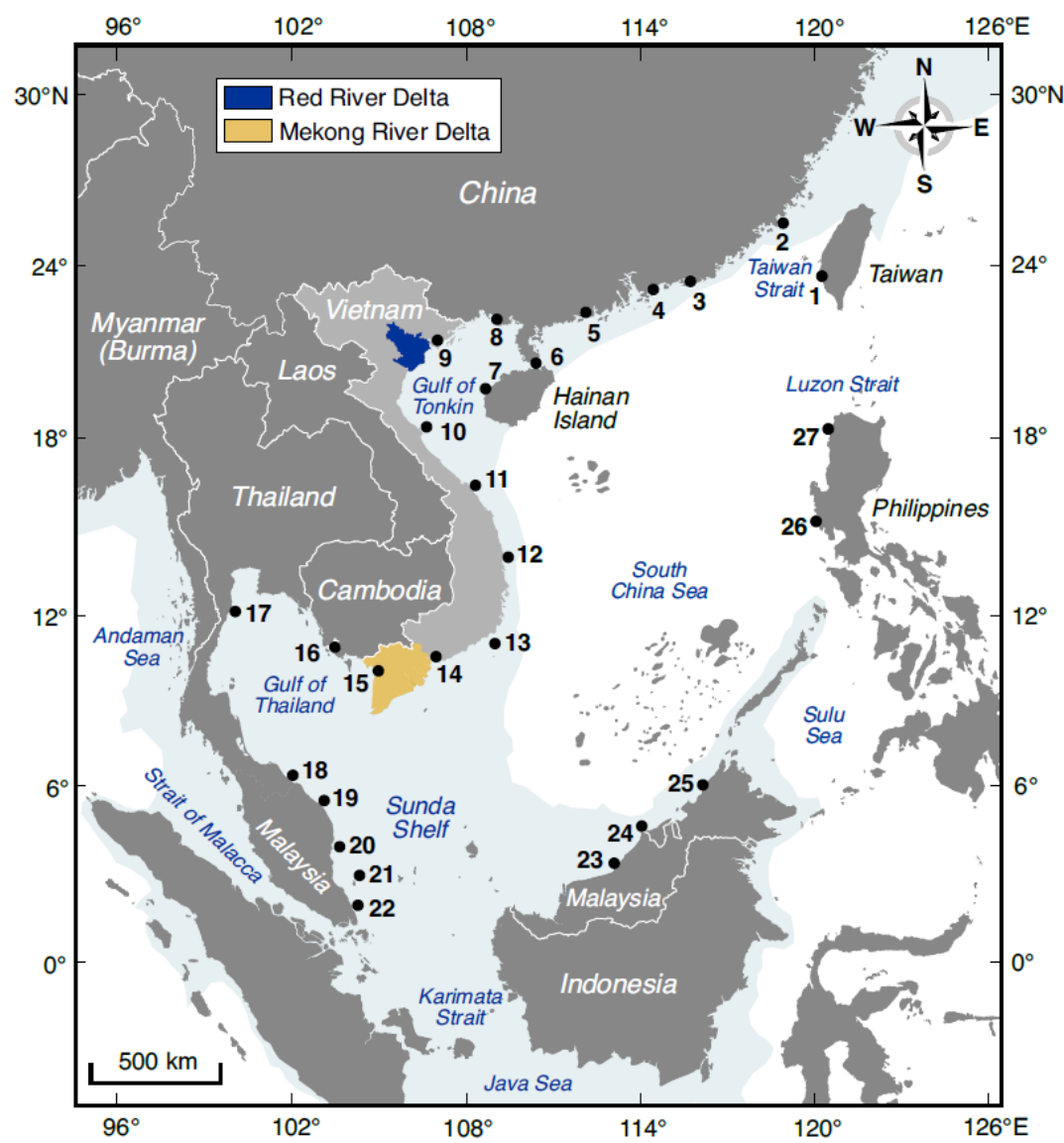

Figure 1 - South China Sea model location, with location of tidal gauges numbered (Table 1) and the rough location of the

Red and Mekong River Deltas highlighted. The shaded blue area, in-sea, shows the approximate coverage of the continental shelf, at $\sim 250 \mathrm{~km}$ depth. 
The Western North Pacific (WNP) basin region accounts for almost one-third of all TC counts globally. WNP TCs (typhoons) are projected to become more intense over the course of the $21^{\text {st }}$ century, with higher category cyclones increasing in frequency (Skliris et al., in review; Emanuel 2021; Knutson et al., 2020; Lap, 2019; Emanuel 2013; Woodruff et al., 2013; Zang and Church 2012; Chan, 2005). In this paper we use a hydrodynamic model to simulate TC induced storm surges for the South China Sea region. South-east Asia has long been identified as a 'hotspot' for projected future mean sea-level rise, plus extremes of sea level related to storm activity (Kirezci et al., 2020; Nicholls and Cazenave, 2010; McGranahan et al., 2007), and our project partnerships provide particular expertise for Vietnam country information; and for the Mekong River delta in particular (Hung et al., 2012). Therefore, we use Vietnam's coastline as the primary location of interest for this paper, and put finer detail along this shore in the hydrodynamic model (Fig. 1). A significant proportion of the country's total population lives along this low-lying coastline or within its two main deltas; the Red and Mekong River deltas (Nicholls et al., 2021; Bangalore et al., 2019; GFDRR., 2015; Hinkel et al., 2014; Dasgupta et al., 2009). The Mekong River delta in the south has been identified as being at particular risk of coastal flooding because mean sea levels have been historically rising here at the same time that mean land elevations have been sinking, and sinking at a faster rate than previously realised (Nicholls et al., 2021; Oppenheimer et al., 2019; GSO, 2019; Minderhoud et al., 2017; Dang et al., 2018; Erban et al., 2014; Hung et al., 2012).

Table 1 - Validation of tidal constituents based on January 2019 tide gauge data. Mean absolute error (MAE) is the mean of absolute difference errors between modelled and measured water levels, over this time, for each gauged location in Fig. 1. The standard deviation around this MAE is also given.

\begin{tabular}{|c|c|c|c|c|c|c|c|}
\hline $\begin{array}{c}\text { Tide } \\
\text { Gauge }\end{array}$ & $\begin{array}{c}\text { ID } \\
\text { (Fig. 1) }\end{array}$ & $\begin{array}{l}\text { Latitude } \\
\text { (degrees) }\end{array}$ & $\begin{array}{l}\text { Longitude } \\
\text { (degrees) }\end{array}$ & $\begin{array}{l}\text { Approx. } \\
\text { mean. tidal } \\
\text { range } 1970- \\
2019(\mathrm{~m})\end{array}$ & $\begin{array}{c}\text { Mean } \\
\text { absolute } \\
\text { error } \\
\text { (MAE, m) }\end{array}$ & $\begin{array}{c}\text { Standard } \\
\text { deviation of } \\
\text { MAE }(\mathrm{m})\end{array}$ & $\begin{array}{l}\text { Correlation } \\
\text { Coefficient }\end{array}$ \\
\hline Kaohsiung & 1 & 22.61 & 120.28 & 0.98 & 0.07 & 0.05 & 0.95 \\
\hline Xiamen & 2 & 24.42 & 118.30 & 8.53 & 0.29 & 0.20 & 0.97 \\
\hline Shanwei & 3 & 22.65 & 115.30 & 3.43 & 0.10 & 0.08 & 0.95 \\
\hline $\begin{array}{l}\text { Hong } \\
\text { Kong }\end{array}$ & 4 & 22.27 & 114.38 & 3.57 & 0.13 & 0.11 & 0.93 \\
\hline Zhapo & 5 & 21.50 & 111.78 & 5.44 & 0.12 & 0.09 & 0.97 \\
\hline Haikou & 6 & 20.02 & 110.28 & 4.01 & 0.24 & 0.17 & 0.77 \\
\hline Dongfang & 7 & 19.10 & 108.62 & 4.57 & 0.16 & 0.12 & 0.94 \\
\hline Beihai & 8 & 21.48 & 108.98 & 7.09 & 0.20 & 0.13 & 0.98 \\
\hline Hon Dau & 9 & 20.67 & 106.82 & 4.83 & 0.32 & 0.25 & 0.89 \\
\hline Vung Ang & 10 & 18.18 & 106.35 & 3.35 & 0.21 & 0.14 & 0.81 \\
\hline Son Tra & 11 & 16.10 & 108.22 & 3.50 & 0.09 & 0.07 & 0.96 \\
\hline Qui Nhon & 12 & 13.77 & 109.38 & 1.28 & 0.16 & 0.13 & 0.85 \\
\hline Phu Quy & 13 & 10.52 & 108.93 & 0.83 & 0.20 & 0.14 & 0.87 \\
\hline Vung Tau & 14 & 10.34 & 107.01 & 5.93 & 0.18 & 0.12 & 0.97 \\
\hline Rach Gia & 15 & 9.99 & 105.07 & 0.80 & 0.12 & 0.09 & 0.84 \\
\hline Phu Quoc & 16 & 10.22 & 103.97 & 0.65 & 0.08 & 0.06 & 0.91 \\
\hline Ko Lak & 17 & 11.79 & 99.90 & 5.70 & 0.15 & 0.09 & 0.93 \\
\hline Geting & 18 & 6.25 & 102.12 & 5.33 & 0.13 & 0.08 & 0.86 \\
\hline Cendering & 19 & 5.26 & 103.23 & 5.39 & 0.16 & 0.11 & 0.92 \\
\hline Kuantan & 20 & 3.97 & 103.44 & 6.78 & 0.19 & 0.12 & 0.93 \\
\hline Tioman & 21 & 2.81 & 103.60 & 6.72 & 0.18 & 0.13 & 0.93 \\
\hline Sedili & 22 & 1.93 & 104.18 & 5.60 & 0.19 & 0.13 & 0.90 \\
\hline
\end{tabular}




\begin{tabular}{|l|c|c|c|c|c|c|c|}
\hline \multicolumn{1}{|c|}{$\begin{array}{c}\text { Tide } \\
\text { Gauge }\end{array}$} & $\begin{array}{c}\text { ID } \\
\text { (Fig. 1) }\end{array}$ & $\begin{array}{c}\text { Latitude } \\
\text { (degrees) }\end{array}$ & $\begin{array}{c}\text { Longitude } \\
\text { (degrees) }\end{array}$ & $\begin{array}{c}\text { Approx. } \\
\text { mean. tidal } \\
\text { range 1970- } \\
2019(\mathrm{~m})\end{array}$ & $\begin{array}{c}\text { Mean } \\
\text { absolute } \\
\text { error } \\
\text { (MAE, m) }\end{array}$ & $\begin{array}{c}\text { Standard } \\
\text { deviation of } \\
\text { MAE (m) }\end{array}$ & $\begin{array}{c}\text { Correlation } \\
\text { Coefficient }\end{array}$ \\
\hline Bintulu & 23 & 3.45 & 113.03 & 4.44 & 0.13 & 0.09 & 0.95 \\
\hline Miri & 24 & 4.39 & 113.90 & 4.70 & 0.08 & 0.06 & 0.97 \\
\hline $\begin{array}{l}\text { Kota } \\
\text { Kinabalu }\end{array}$ & 25 & 5.98 & 116.07 & 5.72 & 0.14 & 0.11 & 0.93 \\
\hline Subic Bay & 26 & 9.75 & 118.30 & 2.94 & 0.07 & 0.06 & 0.96 \\
\hline Currimao & 27 & 14.76 & 120.00 & 2.40 & 0.05 & 0.04 & 0.97 \\
\hline
\end{tabular}

The overall aim of our study is to simulate present and future storm surges and thus estimate extreme sea levels, which fully incorporate the influence of TCs on storm surge dynamics. We couple a hydrodynamic model of the South China Sea with TC tracks from STORM to examine storm surge behaviour under climate change influences. Wind and pressure data comes from two state-of-the-art synthetic STORM datasets for the WNP region. These data are: (1) the past/present dataset (Bloemendaal et al. 2019a) based on IBTrACS observed data for 1980-2018 (Knapp et al., 2010) and (2) the future dataset (Bloemendaal et al. in review) using outputs from the CNRMCM5.1 global climate circulation model (Voldoire et al., 2013), assuming a SSP5-8.5 climate scenario up to the year 2050. Both datasets contain the equivalent of 10,000 synthetic storm-years of TC data ensuring that even very low probability, but highly hazardous, extreme sea levels can, for the first time, be fully represented in a regional analysis.

\section{The hydrodynamic model}

We introduce here the hydrodynamic model, first outlining the model configuration and the specification of local tides. We then document validation of simulated tides and storm surges in the model, using available tide gauge data.

\subsection{Model configuration}

We adapted a DHI MIKE 21 FM (DHI, 2017a) depth-averaged barotropic, hydrodynamic model of the South China Sea; provided by our Vietnam partners (the Southern Institute of Water Resource Research, SIWRR), to simulate local sea levels (Fig. 2). The MIKE 21 FM (flexible mesh) model uses an irregular interconnected triangular mesh to represent the domain area, the benefits of which include optimisation of element size around features of particular interest (creating computation efficiencies where detail is not required) and allowing a more precise representation of potentially ragged coastlines. We reconfigured the land boundary using Prototype Global Shoreline data from the National Geospatial Intelligence Agency (via National Oceanic and Atmospheric Administration; https://shoreline.noaa.gov). The model's coastal boundaries mostly have a grid resolution of $\sim 11$ $\mathrm{km}$ but this reduces to $\sim 7 \mathrm{~km}$ and $\sim 5.5 \mathrm{~km}$ for the shorelines of Cambodia, Thailand and China around Hainan island immediately adjacent to Vietnam, and becomes finer resolution again at $\sim 2.3 \mathrm{~km}$ along the coastline of Vietnam itself. For mesh representing deep water, the grid is not more than $\sim 83 \mathrm{~km}$ across. The mesh size at each the seven open sea boundaries, is approximately $\sim 52 \mathrm{~km}$ in the model. 
(a) Model Mesh and Tidal Boundaries

(b) Bathymetry and Export Points
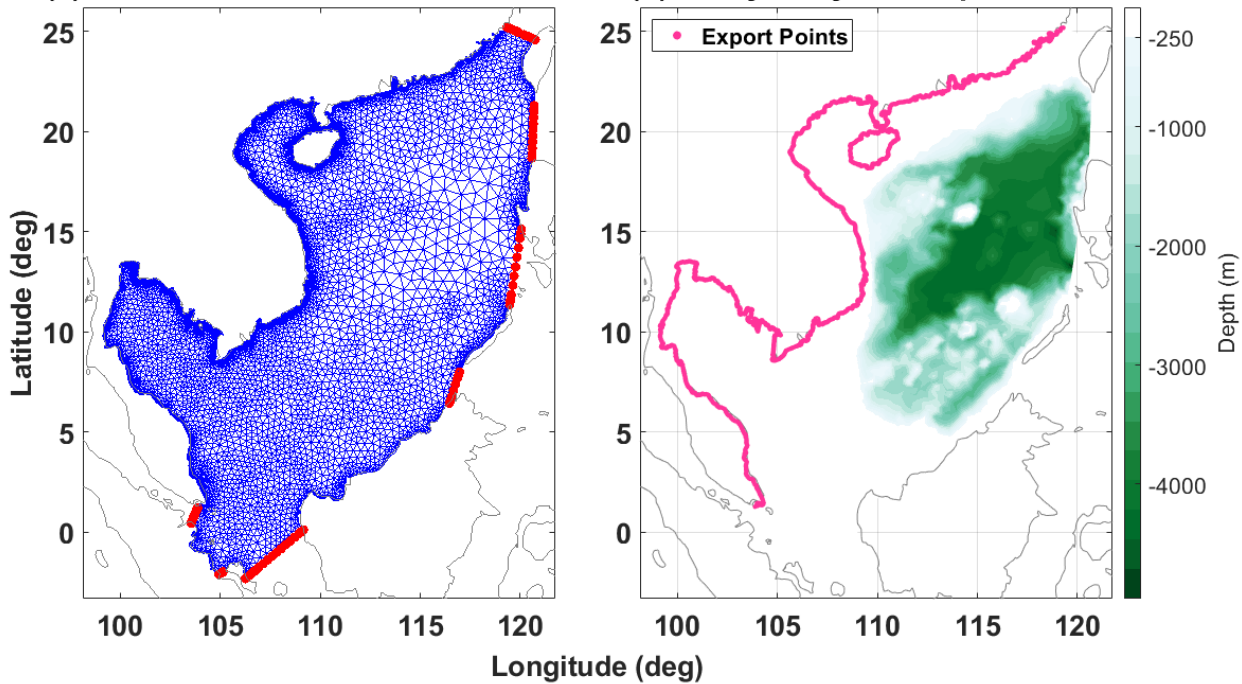

Figure 2 - (a) MIKE 21 FM bathymetry and model mesh for the South China Sea. The irregular triangular mesh grid (blue) is enclosed by land (blue) and water/tidal boundaries (red). (b): SRTM15+ ocean bathymetry (green) and coastline points (pink) exported from the model.

For bathymetry, an updated 15 arcseconds resolution global dataset from SRTM15+ (v2) was used. This data was downloaded from the Scripps Institution of Oceanography website (https://topex.ucsd.edu; Tozer, et al., 2019) and interpolated onto the model grid. All model data therefore is measured using an EGM96 vertical reference datum.

To generate the astronomical tidal component within the domain, the seven model open sea boundaries were driven with tidal levels derived from the China Seas and Indonesia 2016 tidal model solutions of the Oregon State University Tidal Inversion Software (OTIS: Martin et al., 2009; Egbert \& Erofeeva 2002). The tides are provided for eight primary (M2, S2, N2, K2, K1, O1, P1, Q1), two long period (Mf, Mm) and three non-linear (M4, MS4, MN4) harmonic constituents. The harmonic constituents were downloaded from the OTIS web site (http://volkov.oce.orst.edu/tides/). The tide was predicted, for each boundary grid point, using the Tidal Model Driver (TMD) MATLAB toolbox (http://polaris.esr. org/ptm_index.html). Because the model is barotropic ocean currents are not separately incorporated.

\subsection{Model validation: tides}

175 To ensure that our MIKE 21 FM model accurately captures the complex tidal characteristics of the modelled region (Phan et al., 2019) we compared model predictions to the astronomical tidal component, estimated from measured hourly sea level data at 27 tide gauge stations located around the South China Sea (Fig. 1, Table 1; Caldwell, et al., 2015). Extra years of sea level data at four of these tidal gauges (Phu Quoc, Phu Quy, Son Tra, Rach Gia) was also made available directly from SIWRR. Despite there being a good number of tide gauges in

180 the South China Sea region, only a third (Kaohsiung, Hong Kong, Ko Lak, Geting, Cendering, Kuantan, Sedili and Vung Tau) have 30 or more years of data. Annual mean sea level values were computed for each tide gauge, 
and then subtracted from these measured sea level records, to offset each time-series so it was equivalent to the model datum of mean sea level.

To extract just the tidal component from the gauge record, and to remove meteorological influences, we undertook a harmonic analysis on the sea levels using the MATLAB T-Tide software (Pawlowicz et al. 2002). We used the standard set of 67 tidal constituents, for the most recent year with the least amount of missing data. We then used the harmonic constituents at each site, to predict the tide for a randomly chosen period (January 2019). Then the model was run for the same period, just with OTIS tidal forcing at the boundaries and no meteorological forcing. Hourly results were output for the grid points located closest to the 27 tide gauge coordinates. Figure 3 presents the time-series of model-predicted and measured tidal levels at six gauge locations around Vietnam, showing that the model accurately replicates the tidal signals and captures both tidal range and form variations here, as for the entire region.

We calculated the Mean Absolute Error (MAE), and the standard deviation around this MAE, for all 27 grid points (Table 1). The average of all these MAE is $0.15 \mathrm{~m}$, and the average of all the grid points' standard deviation is $0.1 \mathrm{~m}$. This size difference error is consistent with earlier studies simulating extreme sea levels (e.g., Muis et al., 2016; Vousdoukas et al., 2016; Haigh et al., 2014). Table 1 also reveals that locations where tide gauges record diurnal tides, around the Gulf of Tonkin (6-9 in Fig. 1), had the largest MAE and standard deviation of absolute difference error, whereas the locations where tide gauges record semi-diurnal and mixed tides around Vietnam, Borneo and China coastlines (stations 1-5, 10-16, 18-26 in Fig. 1) had chiefly the smallest. The correlation coefficients in Table 1 ranged between 0.77 and 0.98 with the highest correlations in the northern and eastern areas of the model that experience fully- or mainly- semi-diurnal tidal regimes.

We also compared the amplitude and phase of the four main tidal constituents, extracted from the modelled and measured time-series at each of the 27 sites. The model accurately matches tidal constituent observations for most stations but with a slight amplitude underestimation where there are transitioning tidal regimes; such as the amplitude of larger semi-diurnal tides around the Taiwan strait (Xiamen) and mixed diurnal tides around the Gulf

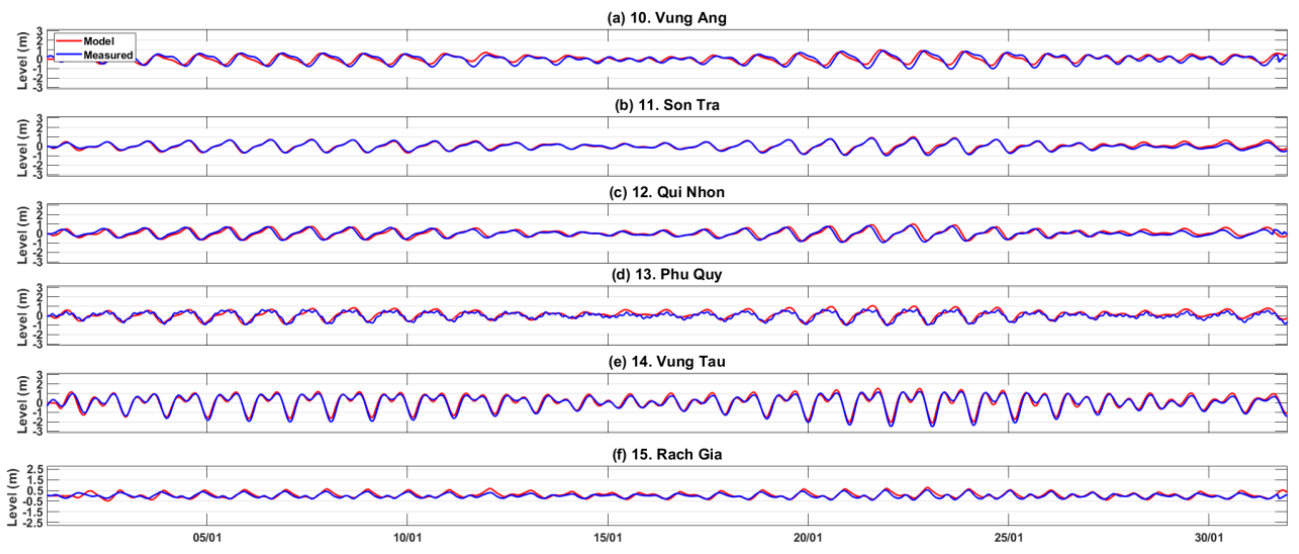

Figure 3 - Comparison of modelled (red) and measured (blue) water level time series (January 2019) at six Vietnamese tide gauge station locations (see Fig. 1 for locations) 
of Tonkin, where higher MAE were observed. Amplitude errors may be due to the absolute decimal accuracy of some tide gauge location coordinates as much as due to model limitations. The mean absolute amplitude error of the $\mathrm{M}_{2}, \mathrm{~S}_{2}, \mathrm{O}_{1}$ and $\mathrm{K}_{2}$ constituents, across all 27 tide gauge sites, are 0.05, 0,03, 0.06 and $0.06 \mathrm{~m}$, respectively (Table 2). The mean absolute phase error of the $\mathrm{M}_{2}, \mathrm{~S}_{2}, \mathrm{O}_{1}$ and $\mathrm{K}_{2}$ constituents are 17, 18, 11 and 12 degrees, respectively (Table 2). Small semi-diurnal $\left(\mathrm{M}_{2}\right.$ and $\left.\mathrm{S}_{2}\right)$ phase differences still exist in the model for stations located around the mixed (mainly diurnal) tide zones of central Vietnam.

Table 2 - Mean absolute amplitude and phase errors of the four main tidal constituents for the 27 validation sites.

\begin{tabular}{|l|c|c|}
\hline Tidal Constituent & Mean absolute amplitude error $(\mathrm{cm})$ [s.d.] & Median absolute phase error (degrees) [s.d.] \\
\hline $\mathrm{M}_{2}$ & $5[4]$ & $16.8[15]$ \\
\hline $\mathrm{S}_{2}$ & $3[2]$ & $18.4[17]$ \\
\hline $\mathrm{O}_{1}$ & $6[6]$ & $11.3[7]$ \\
\hline $\mathrm{K}_{1}$ & $6[6]$ & $11.8[9]$ \\
\hline
\end{tabular}

\subsection{Model validation: storm surges}

In a second validation exercise, we examined the hydrodynamic model's ability to accurately simulate storm surges induced by TCs. The length of measured sea level data was, on average, short across all 27 gauge locations, with many sites only having a few years of data. Consequently, only a small selection of large storm surges is represented in the available tide gauge records and we therefore focused on those select past cyclone events for validation.

Firstly, for data on the TCs in the South China Sea, we utilised the database from version 4.0 of the IBTrACS (https://www.ncdc.noaa.gov/ibtracs/; Knapp et al., 2010). We identified all cyclone events in IBTrACS for the WNP region and for the period 1970 to 2020, which: (1) made land fall along the coast of Vietnam; (2) have matching measured sea level data at a tide gauge close to the land fall location; and (3) capture the storm surge in the measured records for that event. Furthermore, radius to maximum winds information was only available in

230 the IBTrACS data for certain cyclones and this therefore further reduced the possible number of cyclones for validation. A total of five cyclone events matched the above criteria: Typhoon Sally in September 1996; Tropical Storm Linda in October/November 1997; Typhoon Xangsane in September/October 2006; Typhoon Ketsana in September 2009; and Typhoon Mangkhut in September 2018. These cyclones impacted different stretches of coastlines, from the south coast of Vietnam through to the north, and thus provided a range of events suitable to validate the model.

For each storm event, we estimated spatially and temporally varying wind and atmospheric pressure using the IBTrACS data to drive a Holland cyclone model approach (Holland, 1980). The IBTrACS cyclone 3-hourly timesteps, wind speeds, radius to maximum winds and track coordinates were each imported into the MIKE 21 Cyclone Wind Generation tool (DHI, 2017b) to generate unique cyclone wind and pressure files at $0.25^{\circ} \mathrm{x} 0.25^{\circ}$ grid resolution. All IBTrACS cyclones were synthetically reproduced using the Single Vortex Holland option, with the Holland B parameter estimated using the Holland Formula specified in Harper and Holland (1999). 
Secondly, for each of the five cyclone events, we ran a parallel simulation with spatially and temporally changing wind and atmospheric pressure fields from the ERA5 reanalysis (Hersbach et al., 2018) for validation. These data were obtained from the Copernicus climate data store (https://cds.climate.copernicus.eu/), for the known cyclone dates, on a regular $0.25^{\circ} \times 0.25^{\circ}$ grid at hourly resolution. Wind and pressure data were clipped to the area of interest and reformatted into a MIKE 21 FM grid file format without further modification. Finally, for each of these same five cyclone events, we also created a corresponding 'tides-only' run, without any meteorological forcing, so we could isolate the storm surge components in each simulation.

(a) Total water levels

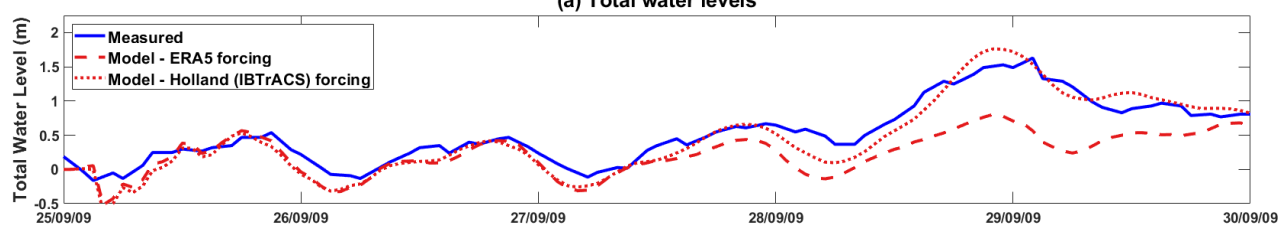

(b) Surge levels

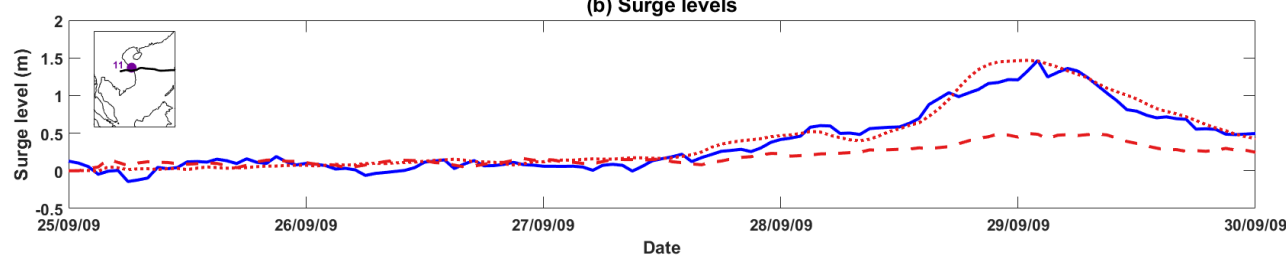

Figure 4 - Validating modelled surges using ERA5 (red dashed) and Holland Model using IBTrACS (red dotted) wind and pressure fields against measured data (blue): Typhoon Ketsana surge at tide gauge 11: Son Tra (inset or see Fig. 1 for location) in September 2009. Firstly (a) comparing total sea levels, and then (b) comparing surge-only water levels.

Using these meteorological forcing methods, the hydrodynamic model was able to closely predict the total sea level (i.e., tide plus storm surge component), at the nearest tide gauge to where the cyclone made landfall, for each of the five events. To illustrate, we show Holland model-derived and ERA5 validation results for Typhoon Ketsana, which made landfall close to the tide gauge at Son Tra, Vietnam (11 in Fig. 1) in September 2009, producing a storm surge of approximately $1.5 \mathrm{~m}$. A comparison of the modelled and measured total sea levels for this event is shown in Fig. 4a, with the isolated storm surge component shown in Fig. 4b. While the simulations using the IBTrACS meteorological forcing generated using a Holland model approach accurately capture the height of both the maximum sea level and the storm surge component (MAE $=0.18 \mathrm{~m}$ ), the simulation driven with the ERA5 meteorological forcing significantly underestimates both the maximum sea level and the storm surge component $(\mathrm{MAE}=0.40 \mathrm{~m})$. Similar results (not shown), favouring the IBTrACS/Holland approach over ERA5 reanalysis, were obtained for all of the other four cyclone events considered. Overall, these validation findings provide confidence that the hydrodynamic model is able to accurately capture both total sea levels and the storm surge component of cyclone events, when the Holland meteorological forcing approach is used.

\section{Simulating present and future extreme sea levels}

We now present the methodology for simulating storm surges alone, estimating extreme sea levels (storm surge and tides together), and calculating the associated statistics. First, we outline the datasets used to obtain the 

surges and extreme sea levels.

\subsection{STORM dataset}

To estimate changes in storm surge and total sea level we utilised synthetic TC data from the STORM (Statistically generated Tropical stORM) database, created by Bloemendaal et al. (2020) for a present period and Bloemendaal et al. (in review) for a future period. For the past/present database, the STORM algorithm was applied to TCs from 38 years of historical IBTrACS data (1980-2018) to statistically extend this original record into the equivalent of 10,000 years of TC activity (Bloemendaal et al., 2020). This past/present data henceforth will be referred to as baseline data. Validation showed that STORM preserves the TC statistics found within the original 38-year dataset. The STORM database provides 3-hourly information on an individual cyclone's location, wind speed, pressure, radius to maximum winds and storm category.

From the baseline STORM data set, we extract all WNP area TCs that reach at least hurricane strength (Category 1 or greater on the Saffir-Simpson Hurricane Wind Scale; Simpson and Saffir, 1974). Globally, this amounts to 156,879 cyclones. TCs outside the model domain or those that were short lived ( $<9$ hours) were also removed, leaving a subset of just over 30,800 individual cyclone-candidates for model simulation.

For the future STORM database, Bloemendaal et al. (in review) extracted modelled cyclone events from four climate models; CMCC-CM2-VHR4, CNRM-CM6-1, EC-Earth3P-HR and HadGEM3-GC31-HM; each of which had been run at a high spatial resolution for the period 2015-2050 and forced with emissions representative of the SSP5-8.5 climate change scenario. This scenario represents unconstrained growth in economic output and energy, which exploits abundant fossil fuel resources and relies on global markets and technological progress to achieve sustainable development (IPCC, 2019). It is the highest greenhouse gas emissions pathway, linked to greater reliance on adaptation than mitigation to address climate challenges. Using a delta approach (contrasting present and future climate outcomes, see Bloemendaal et al., in review), the authors then statistically created synthetic events representative of 10,000 years of TC activity, for each of the four future climate simulations. Overall, the STORM database shows a decrease in frequency of TCs globally, including in the WNP region, but we found in the area of our smaller model domain, all four future STORM datasets show an increase in TC frequency. While the majority of storms were uncategorised, there was a trend for a greater proportion of TCs to reach intense levels, compared to the baseline data (Table 3).

Table 3 - Number of TCs of each category (using Saffir Simpson scale) within the wider WNP STORM baseline and future datasets.

\begin{tabular}{|l|c|c|c|c|c|c|}
\hline & $\begin{array}{c}\text { Tropical } \\
\text { Storm/Depression }\end{array}$ & 1 & 2 & 3 & 4 & 5 \\
\hline STORM Present & 255,441 & 48,350 & 28,991 & 36,499 & 41,391 & 1,648 \\
\hline STORM Future-CNRM & 294,108 & 41,307 & 28,411 & 34,846 & 52,068 & 14,580 \\
\hline STORM Future-EC_Earth & 273,700 & 47,456 & 33,076 & 41,553 & 57,775 & 11,760 \\
\hline STORM Future-HadGEM & 265,767 & 45,826 & 32,529 & 40,834 & 56,943 & 21,661 \\
\hline STORM Future-CMCC & 286,883 & 49,002 & 31,315 & 37,310 & 49,626 & 9,424 \\
\hline
\end{tabular}


Because of the large computational cost of simulating the sea level conditions associated with the equivalent of 10,000 years of cyclone activity, we use data from only one climate model to represent future TC activity. The STORM dataset based on the CNRM-CM6-1 climate model was selected as it most closely follows the trend of decreased frequency of TCs in the WNP (compared to baseline), having the smallest total number of hurricane strength storms in the output. Furthermore, when comparing the number of the stronger TCs in the dataset, between all climate models, CNRM-CM6-1 is middle ranking. Applying the same filtering criteria as for the baseline data above, we were left with over 63,300 individual cyclone tracks. The track density of the baseline and future cyclones is shown in Fig. 5a, and Fig. 5b, respectively. Differences are shown in Fig. 5c, highlighting that there is an increase in frequency of cyclones along the coastline of Vietnam in particular.

(a) STORM Present paths

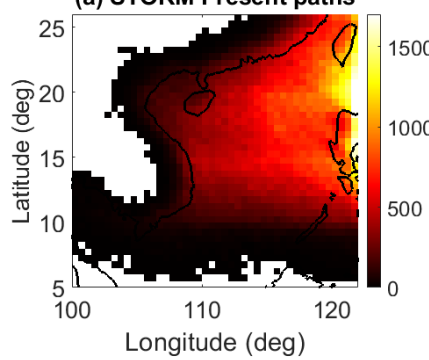

(b) STORM Future paths

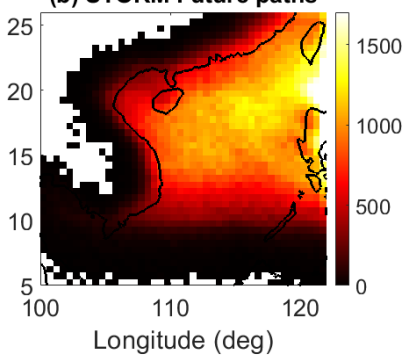

(c) Difference

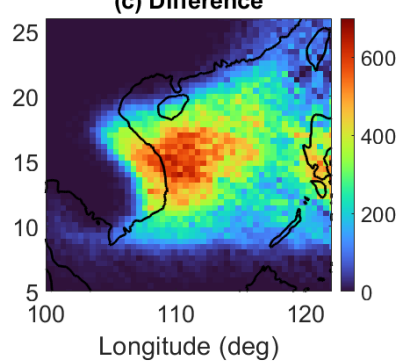

Figure 5 - Left: Baseline STORM track density of Saffir Simpson Category 1+, Middle: CNRM climate model- Future STORM track density, of Saffir Simpson Category 1+, and Right: The cyclone path density difference between them (Saffir Simpson Category 1+ only - i.e. excluding Tropical Storms).

\subsection{Hydrodynamic model implementation}

The first requirement before running baseline and future simulations in the MIKE $21 \mathrm{FM}$ model is to import the STORM-derived information, for each individual TC, into the MIKE 21 Cyclone Wind Generation toolbox. This was done using a MATLAB script with inputs, for each TC, of wind speed, radius to maximum winds and track coordinates, from STORM. The Cyclone Wind Generation toolbox utilised the Single Vortex Holland option, with the Holland B parameter estimated using the Holland Formula specified in Harper and Holland (1999). The output was cyclone wind files for MIKE $21 \mathrm{FM}$ to use at $0.25^{\circ} \mathrm{x} 0.25^{\circ}$ resolution.

MATLAB scripts were also used to generate associated steering files. We initialised each model simulation at the timestep at which the synthetic cyclone started or entered our grid domain, and terminated the run at the time-step the cyclone exited the domain or dissipated. Time-series results were set to export at a 10-minute temporal resolution for each simulation. Individual MIKE 21 model simulation were performed on the University of Southampton's IRIDIS 5 High Performance Computing Facility, taking an average of 15 minutes to complete.

For reasons of data economy, we chose to only save (output) predicted surge time-series at discrete points for each simulation, rather than across the 13,350 nodes of the entire grid domain. These discrete 3,051 output coastline points (OCP) are located along the length of the Chinese, Vietnamese, Cambodian and Thai (and half of 
Malaysian) coastlines in the model, at separation distance of approximately $2 \mathrm{~km}$ to $5 \mathrm{~km}$ (OCP are shown in pink in Fig. 2).

Before running the models, we checked if non-linear interactions between the tide and non-tidal components would influence model output of sea level levels in this region (Idier et al., 2019; Horsburgh and Wilson, 2007).

Flood hazard can be underestimated if these non-linear interactions are not accounted for (Arns et al. 2020; Williams et al., 2016). We determined that the differences in the height and duration of storm surge is negligible, with only the timing of the surge peak nominally impacted between high and low water tidal states (see Appendix A, Fig. A1). We therefore implemented all model simulations as meteorological forcing only ('surge-only') so that surge levels would subsequently be added to a randomly selected tide in the subsequent computation of total sea level return periods.

\subsection{Computation of return periods}

Upon completion of all the simulations, each OCP has estimated surge levels from a very large number of individual cyclones, for both the baseline (1980-2018; 30,800 cyclones) and future (2015-2050; 63,300 cyclones) model outcomes. Because model outputs represent a synthetic record of 10,000 years duration, for each of the baseline and future periods, this allows for a robust estimation of even extreme return period levels (RPL) at every OCP. In estimating these RPLs, we employed the following methodology: (i) the annual surge maxima was found for every one of the 10,000 years of the synthetic record, for each OCP; (ii) these maxima surge levels were then sorted in descending order and given a rank $(m)$ before; (iii) the probability of exceedance $(P)$ was calculated using the Gringorten formula:

$$
P=\frac{(m-a)}{(n+2 a)}
$$

where $a$ is scale parameter equal to $0.44, n$ is the number of extreme values. The RPL therefore is given as 1/P. The Gringorten formula was used due to its suitability for extreme value estimation (irrespective of sample size) and past record in unbiased return period estimation (Guo, 1990).

We also estimated total sea level return periods for each coastal output point. To do this, we ran a tide-only simulation for a random year (2009), saving 10-minute predicted tidal levels at each of the OCP. A year of data is sufficient to extract the tidal constituent information required to characterise other tide-years and to fully represent the lunar perigee and nodal astronomical tidal cycles. We then analysed the tidal predicted time-series using the MATLAB T-Tide script (Pawlowicz et al., 2002) to define the tidal constituents and thereby predict the tide for the 19-year period from 2003 to 2021 . This 19-year period was selected because it encompasses the full 8.85-year cycle of lunar perigee and the 18.6-year nodal astronomical tidal cycle, both of which can influence extreme sea levels (Baranes et al., 2020; Peng et al., 2019; Haigh et al., 2011). In the baseline and future STORM dataset, TCs only occur in the months of May to November. We therefore randomly combined the annual maximum surge level, for each OCP, with a random tidal level from the May to November periods of the 19-year simulated tidal record for that same OCP. We then calculated total sea level return periods for this combined sea level record, using the method described above. This above RPL estimation process was repeated 100 times in a 
Monte Carlo approach with the mean return period level computed for all 100 scenarios. For reference, the way the modelling was set up, either peaks over threshold or annual maxima methods could be employed for statistical estimation of RPLs. However, because our interest is in selecting surge peaks (TC events) which are independent of one another, and it is not known if the assumption of complete TC independence in the STORM datasets is valid, we selected the annual maxima approach, as the data was plentiful.

\section{Results}

We now present the results of our approach, first illustrating the synthetic cyclone data outputs, followed by the associated extreme statistics. Firstly attributed to the storm surge alone, and then additionally accounting for other influences on sea level (tides and absolute mean sea-level rise).

\subsection{Cyclone tracks}

To illustrate how the orientation and strength of cyclones varies in our baseline simulations, Fig. 6 shows the track of the synthetic cyclones responsible for the 10 largest surges at 12 random equidistant point locations along the modelled coastline of Vietnam and China. There are clear differences, moving geographically north to south, in the origins and magnitudes of each cyclone. But what they all have in common is they pass to the south/west of each point as the TCs travel westwards within the domain. This is expected, as the Coriolis effect pushes winds in a cyclonic (counter-clockwise) direction in the northern hemisphere, and it is the strong onshore winds in the first and second cyclone quadrants that are responsible for generating a large part of the storm surge.

\subsection{Extreme storm surge return period levels}

First, we focus on the surge-only return period levels. Figures 7a,b \& c illustrate the computed 10\% AEP (1:10 year), 1\% AEP (1:100 year) and 0.1\% AEP (1:1000 year) RPLs respectively, for the baseline (1980-2018) scenario. RPLs are slightly higher along the Chinese coastline, reflecting the more frequent cyclone activity in this region of the model domain (Fig. 5a, Fig. 7b, Fig. 7c), with the peak 1\% AEP surge-only RPL reaching 3.5 $\mathrm{m}$ at one OCP here. The shape of the coastline has a strong modulating effect on surge height, that is especially noticeable for the more extreme events, whereby the modelled surges are typically amplified within the many bays, river mouths and inlets located along this northern coastline (Jelesnianski, 1972). Another effect of the shape of the shore is seen along the Vietnam central coastline, where surge RPLs are substantially lower (1\% AEP is $0.3 \mathrm{~m}$ ) than the coastlines of north and south Vietnam. The narrow width of the continental shelf in central Vietnam dampens surge behaviour, that is noticeable even for the most extreme events (Fig. 1, Fig.7b, Fig. 7c). The correlation between storm surge height and continental shelf width is a well-documented characteristic (Pugh and Woodworth, 2014). 
https://doi.org/10.5194/nhess-2021-397

Preprint. Discussion started: 17 January 2022

(c) Author(s) 2022. CC BY 4.0 License.

(c) (1)
Natural Hazards 웅 and Earth System Sciences

Discussions
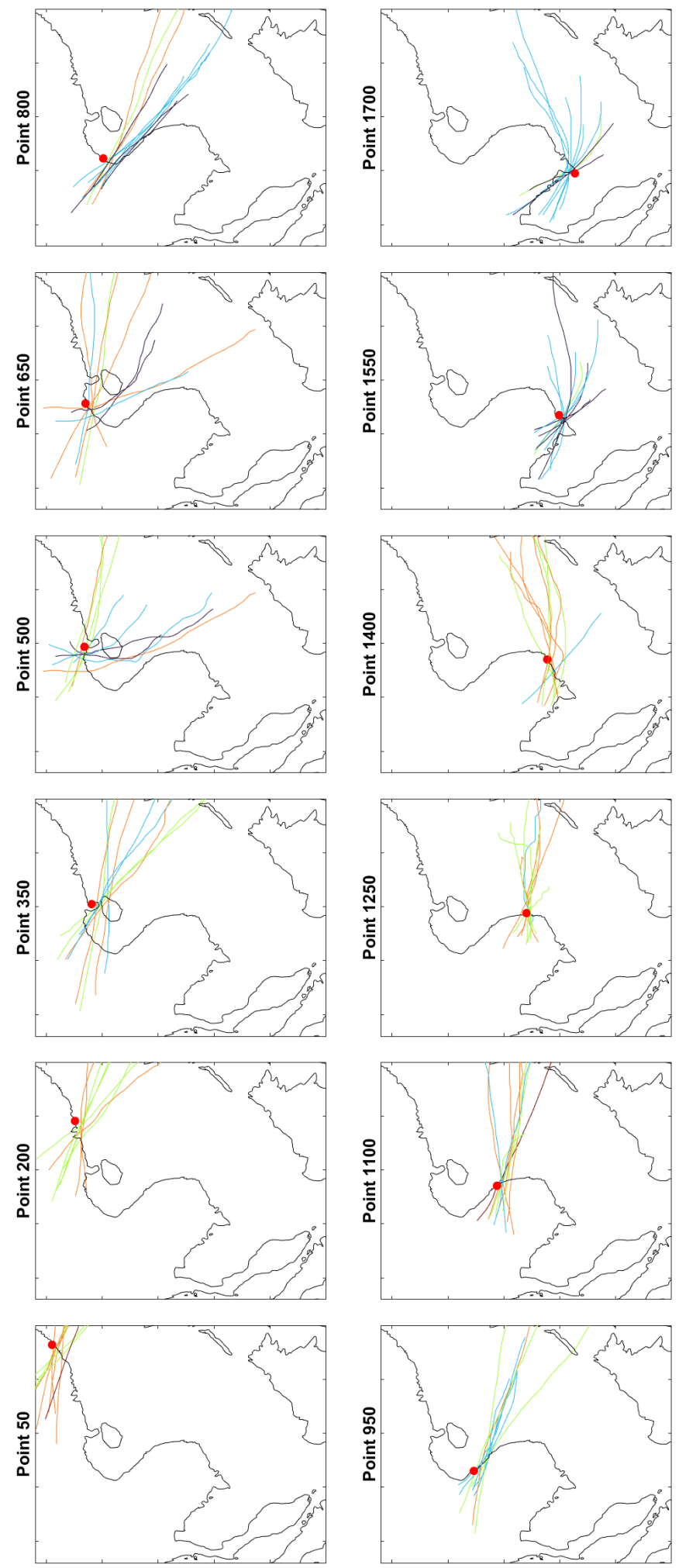

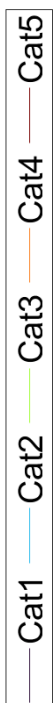

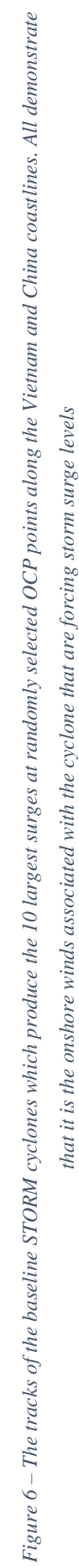


$10 \%$ AEP
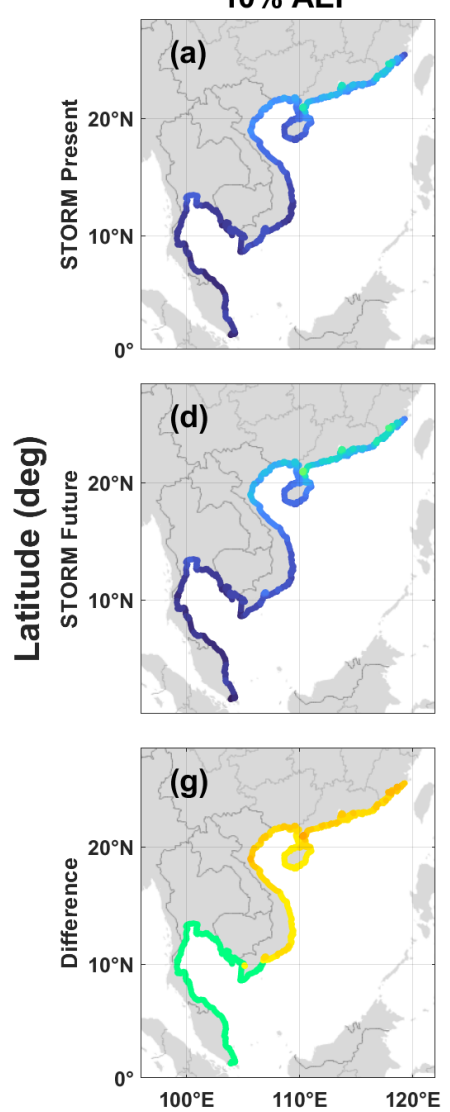

$1 \%$ AEP
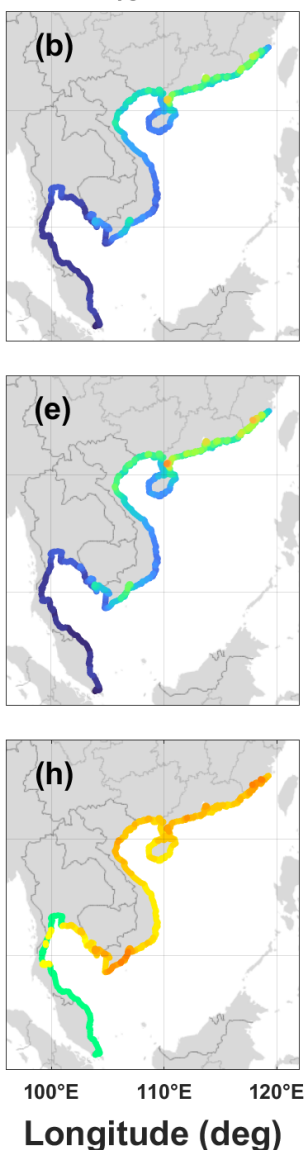

\section{$0.1 \%$ AEP}
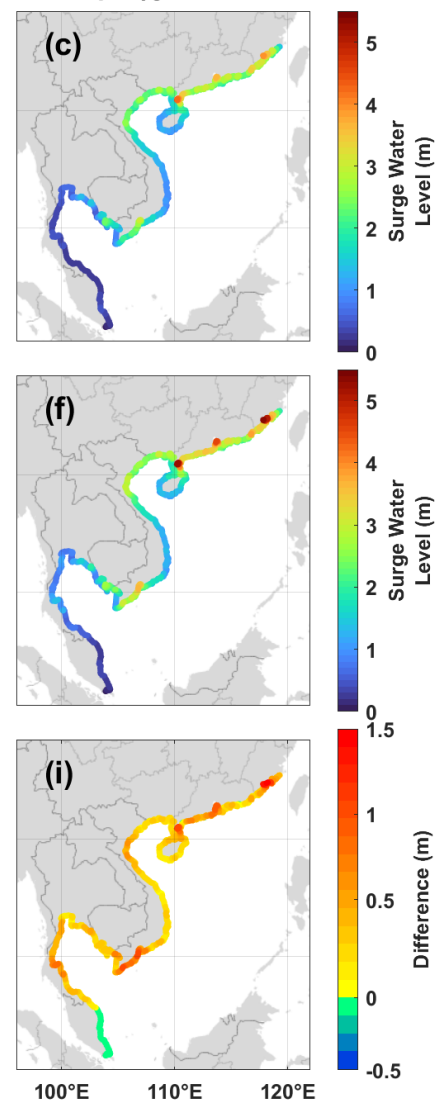

Figure 7 - The $10 \%$ AEP $(a, d, g), 1 \%$ AEP (b,e,h) and $0.1 \%(c, f, i)$ AEP return period water levels (surge only) for the China, Vietnam, Cambodia, Thailand and Malaysian coastlines in the model, using first row: STORM baseline data (1980-2018), second row: CNRM climate model STORM Future data (2015-2050), third row: a difference plot to highlight the areas with greatest change in surge level between STORM baseline and STORM future model results.

For the future period (2015-2050), 10\% AEP, 1\% AEP and 0.1\% AEP RPLs are shown in Fig. 7d, Fig. 7e and Fig., $7 \mathrm{f}$ respectively. In the model coastline between China and Malaysia, future surge levels increase substantially as a consequence of climate change influences compared to the baseline period. In the 1\% AEP hazard scenario, the length of coastline that is exposed to storm surge levels of $2.5 \mathrm{~m}\left(95^{\text {th }}\right.$ percentile storm surge level) or greater more than doubles over the next 30 years, from $353 \mathrm{~km}$ to $930 \mathrm{~km}$, extending from Chinese coastlines (Fig. 7b) into parts of north and south Vietnam (Fig. 7e).

For the more extreme $0.1 \%$ AEP scenario, there is approximately $231 \mathrm{~km}$ of mostly Chinese coastline that we estimate currently has $3.5 \mathrm{~m}\left(\sim 95^{\text {th }}\right.$ percentile storm surge level) or greater storm surge levels (Fig. $\left.7 \mathrm{c}\right)$, but this increases to around $577 \mathrm{~km}$ of coastline with future TCs conveying these highest storm surges also into north and south Vietnam (Fig. 7f). The spatial distribution is greater but so also are storm surge heights. The greatest $1 \%$ 
AEP level increase is approximately $0.8 \mathrm{~m}$ around the south Vietnam coastline (Fig. $7 \mathrm{~h}$ ). The greatest $0.1 \%$ AEP level increase is around $1.6 \mathrm{~m}$ along the Chinese coastline (Fig. 7i). The shape of the coastline, specifically a wide and gently sloping continental shelf and the angle of cyclone approach contribute to this amplification of the more extreme RPLs around these particular coastlines, notably including around the Red and Mekong River deltas (Fig. 1; Ramos-Valle et al., 2020; Pandey and Rao 2019; Bloemendaal et al., 2019b; Poulose et al., 2018).

The baseline model outputs indicate that the coastlines of Cambodia, Thailand and (partial) Malaysia are currently unaffected by storm surges linked to lowest category TCs, storms and depressions. This is expected, as these coastlines have historically rarely experienced cyclone induced storm surges of magnitude (>10\% AEP). And for more likely storm surge events up to the $10 \%$ AEP level, this is predicted to continue into the future too (Fig. 7d). Present storm surge heights along these coastlines average around $0.36 \mathrm{~m}$ and between today and mid-century there is zero increase at $10 \%$ AEP scenario levels. However, at more extreme storm surge probabilities by the year 2050, sections of this coastline are projected to experience storm surges up to $0.6 \mathrm{~m}$ (1\% AEP) and $0.8 \mathrm{~m}$ (0.1\% AEP) higher than current levels (Fig. 7h, Fig. 7i). In some locations this doubles the current storm surge heights.
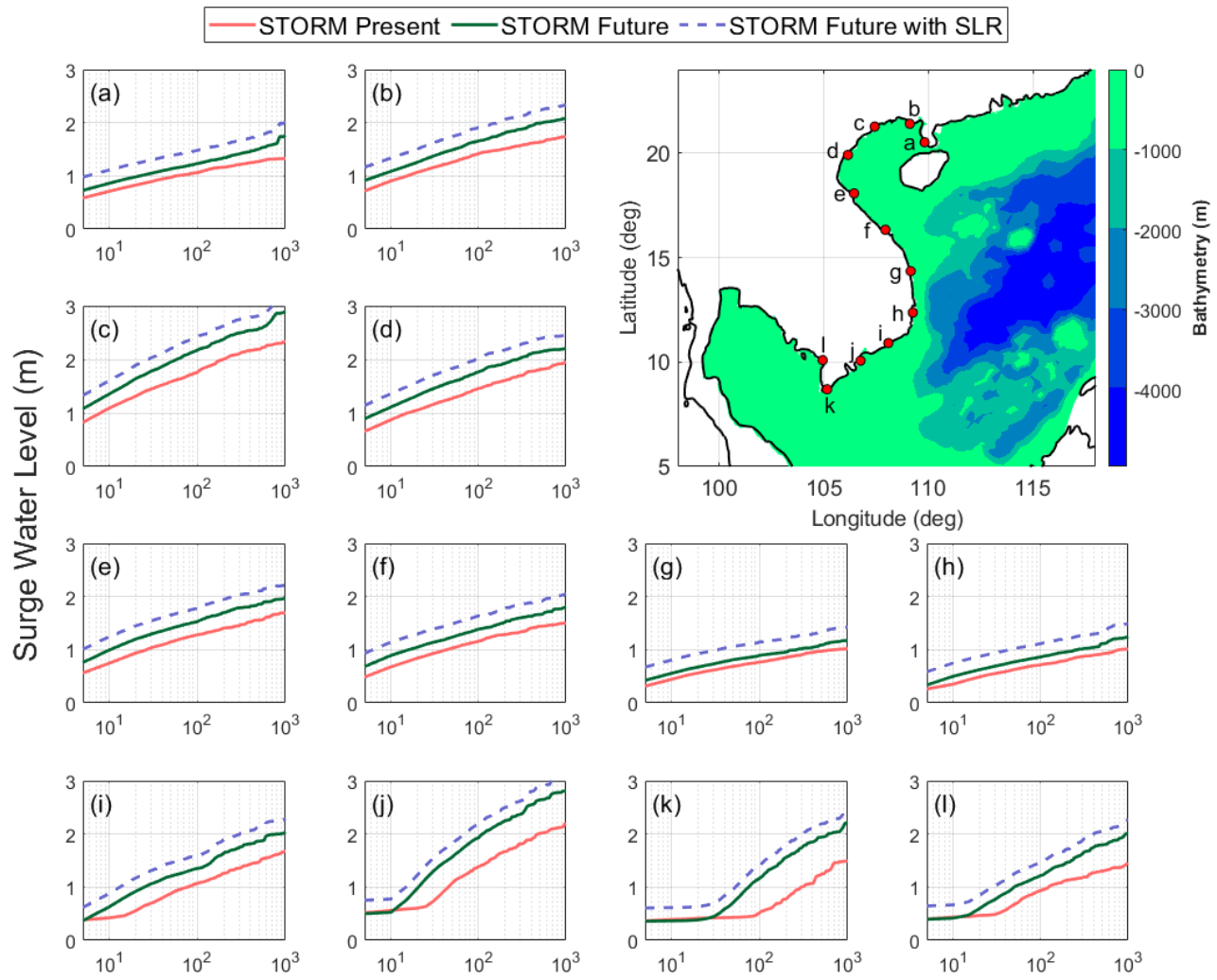

Return Period : 1 in $\mathrm{X}$ years $(\log 10)$

Figure 8 - The relationship between synthetic baseline (pink) and future (green) 'surge-only' return period water levels (Log scale, 1:X years) at equidistant locations at and around the Vietnam coastline. Future return periods with 0.25 mean sealevel rise (SLR), due to climate change by 2050, is shown with a dashed blue line. 
In order to analyse more closely potential impacts to the study Vietnam coastline, we produced flood frequency plots for 12 equidistant selected points, as shown in Fig. 8. These plots illustrate findings that storm surge RPLs are lowest around the central Vietnam coastline (points g,h), where the narrow continental shelf relatively dampens surge height. In both baseline and future scenarios within this central zone, the difference between the smallest (20\% AEP, 1:5 year) and largest (0.1\% AEP, 1:1000 year) RPLs is less than $1 \mathrm{~m}$. This illustrates that the dampening effect provided by the coastal morphology extends to even the most severe storm surges. Additionally, it is possible to see that the biggest growth in modelled storm surge heights over the next 30 years can be found in the southern part of Vietnam. The future 1\% AEP storm surge near to the Mekong River delta (points $\mathrm{j}, \mathrm{k}$ ) for example is average $0.6 \mathrm{~m}$ higher than the current $\sim 1 \mathrm{~m}$ storm surge value, while at the northern coastline of Vietnam near to the Red River delta (point d), the storm surge difference is only around $0.3 \mathrm{~m}$. It is half this again at around $0.12 \mathrm{~m}$ difference for the same $1 \%$ AEP return period in the sheltered central zone (points $\mathrm{g}, \mathrm{h}$ ).

The low-lying Red and Mekong River deltas are both subject to larger storm surge heights due to their location and orientation when future TC behaviour changes in the region over the next 30 years. Both deltas are more densely populated than the national average (and have significant agriculture and infrastructure capital), therefore storm surges present a particular hazard to these areas (Edmonds et al., 2020; Hung et al., 2012; Nguyen et al., 2007). Not only are model projections indicating that by 2050 extreme storm surge levels will be comparatively higher than neighbouring locations, but these results suggest that storm surges would occur more frequently compared to today. For example (excluding tide and mean sea-level rise contributions), storm surge levels associated with a $1 \%$ AEP event near to the Red River delta (Fig. 8d) today would correspond to a 3.3\% AEP (1:30 year) frequency by 2050. Levels associated with a $1 \%$ AEP event at Ho Chi Minh City near to the Mekong River delta (Fig. 8j) today would likely occur at close to $2.8 \%$ AEP (1:35 year) frequency by 2050.

\subsection{Extreme total sea level return period levels}

Representative total sea levels (surge + tide) for the 10\% AEP, $1 \%$ AEP and $0.1 \%$ AEP return period events for both the baseline and future scenarios are illustrated in Fig. 9. A comparison against Fig. 8 shows that tides intensify storm surge hazard by as much as $2 \mathrm{~m}$ along the Chinese coastline, the Gulf of Tonkin, south Vietnam and southern Thailand. Elsewhere tides add between $0.3 \mathrm{~m}$ and $1 \mathrm{~m}$ to surge levels. For the Mekong delta region in the baseline scenario, the mean 1\% AEP total sea level is approximately $1.9 \mathrm{~m}$ above mean sea level (amsl), and in the future the $1 \%$ AEP mean total sea level would be approximately $2.2 \mathrm{~m}$ amsl; an increase of $0.27 \mathrm{~m}$ over the intervening 30 years. For the Red River delta region the baseline 1\% AEP mean total sea level is approximately $2.1 \mathrm{~m}$ amsl and by 2050 this would increase to approximately $2.4 \mathrm{~m}$ amsl. The equivalent increase between the more extreme $0.1 \%$ AEP baseline and future mean total sea levels is estimated to be around $0.36 \mathrm{~m}$ for the Red River delta and $0.56 \mathrm{~m}$ for the Mekong River delta. 


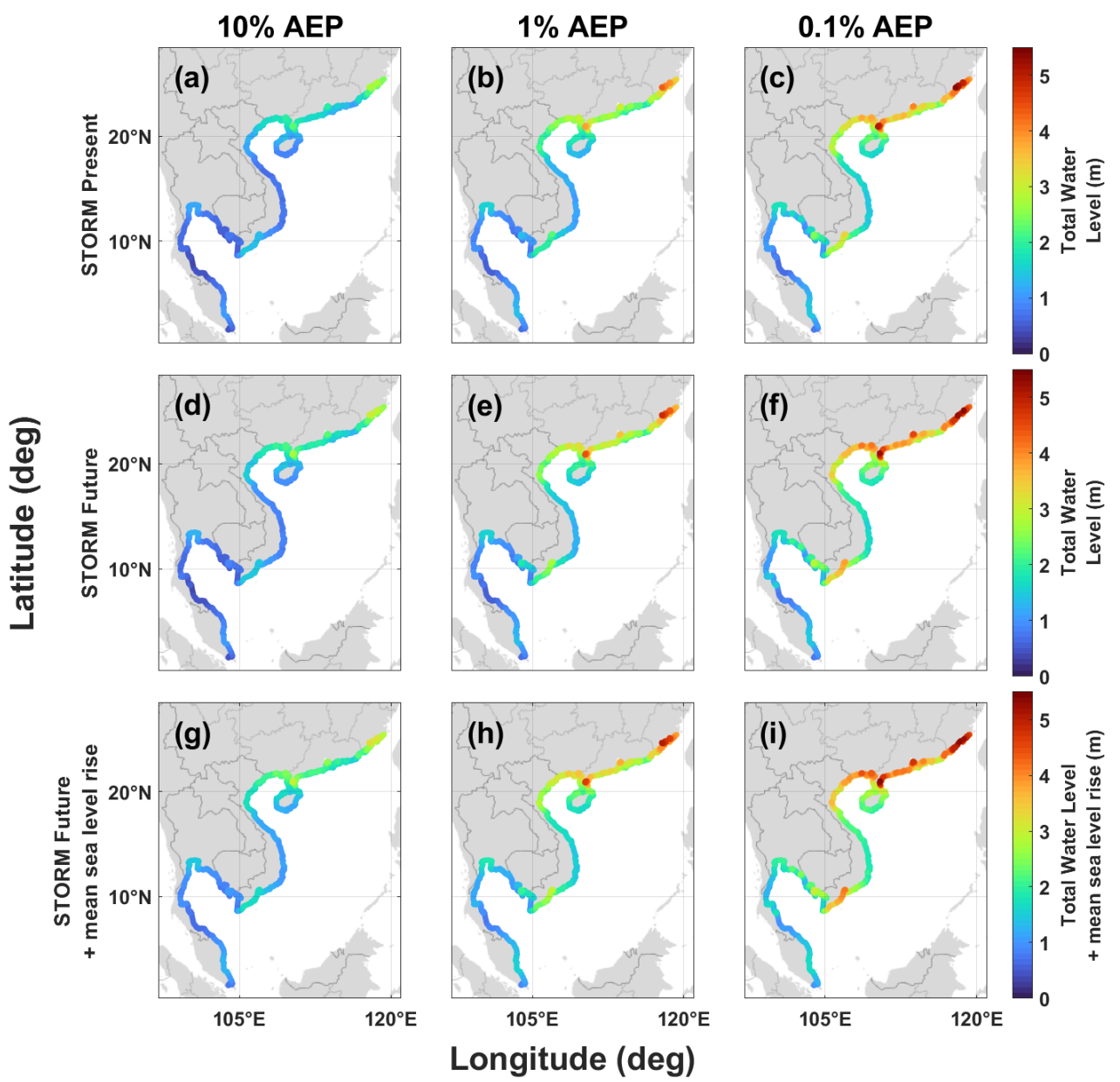

Figure 9 - The 10\% AEP (a,d,g), $1 \%$ AEP (b,e,h) and $0.1 \%(c, f, i)$ AEP return period total sea levels (tide + surge) for the China, Vietnam, Cambodia, Thailand and Malaysian coastlines in the model, using first row: STORM Baseline data (19802018), second row: CNRM climate model STORM Future data (2015-2050) total sea levels, third row: CNRM climate model

STORM Future data total sea levels with 0.25m addition for rising mean sea levels along Vietnam coastline by 2050.

We also account for the added influence of mean sea-level rise to the middle of this century (absolute sea-level rise - i.e. ignoring other factors such as delta subsidence). The IPCC's $6^{\text {th }}$ Assessment Report estimate of projected mean total sea-level rise (relative to a 1995-2014 baseline) along the coastline of Vietnam is $0.25 \mathrm{~m}$ by the year 2050, under the SSP5-8.5 reference scenario (NASA sea-level tool: https://sealevel.nasa.gov/ipcc-ar6-sea-levelprojection-tool). Figure $9 \mathrm{~g}$-i shows the $10 \%$ AEP, $1 \%$ AEP and $0.1 \%$ AEP return period with $0.25 \mathrm{~m}$ of mean sea-level rise simply added (we ignore any indirect effects). Adding a mean sea-level rise to the future $1 \%$ AEP mean total sea levels takes these levels to approximately $2.7 \mathrm{~m}$ amsl for the Red River delta and $2.4 \mathrm{~m}$ amsl around the Mekong River delta. What is notable in Figures 7 to 9 is that by 2050, along many points on the Vietnam and Chinese coastlines, the scale of increase in storm surge regularly surpasses the $0.25 \mathrm{~m}$ size of projected sea-level rise. This holds true for $1 \%$ AEP return periods, and the magnitude of the effect increases as events become more 
extreme (up to $0.1 \%$ AEP). The exception to this result is at the central coastline of Vietnam where surge levels are consistently dampened, even at extreme probabilities, as discussed previously.

\section{Discussion}

In this paper, we have compared projected surge and total sea level return periods, for baseline and future periods, using synthetic TC climatologies generated using the state-of-the-art STORM database. STORM provides the equivalent of 10,000 years of synthetic TC activity, enabling reliable analysis of even low probability, high impact, storm surge events on local sea levels. There is a projected shift in TC intensity and spatial distribution by the year 2050 in the CNRM-CM6-1 global climate model used in this analysis, and this influence is reflected both in raised storm surge heights along lengths of the Chinese and Vietnamese coastlines in the future, and the broadening extent of storm surge activity into southern Vietnam, Cambodia and Thailand. Specifically, our analysis shows that the maximum storm surge heights along Chinese and Vietnamese coastlines increase by up to $0.8 \mathrm{~m}$ (1\% AEP; 1:100 year) and $1.6 \mathrm{~m}$ ( $0.1 \%$ AEP; 1:1000 year) over the next 30 years. It has been established that over the last 30 years TCs have been gradually migrating polewards and achieving their maximum intensity in more northern latitudes (Kossin et al., 2014). A trend that is expected to continue into the future and is represented in the future STORM data too, alongside the aforementioned wider dispersion. This, along with the projected density of TC strikes, will exacerbate predicted storm surge heights in the northern coastlines of our model domain.

485 Cyclone approach angle means that some north and western stretches of coast in the model domain (Fig. 1) are naturally more vulnerable than others over time, irrespective of their coastal morphologies (Pandey and Rao, 2019). However, future increases in surge heights along the central Vietnamese coastline are actually much smaller than the average, even though this part of the coast is most exposed to increases in the frequency and intensity of TCs that induce storm surges (Fig. 5c). Surge heights are dampened here because there is no wide and gently sloping continental shelf to amplify storm surge energy, and few coastal inlets and river mouths along this section to funnel and enhance storm surge wave heights (Dube et al., 1981; Jelesnianski, 1972).

The present frequency of large TCs making landfall and TC-induced storm surges in northern Vietnam is much greater than in the south, and while awareness of the risk is moderately good in south Vietnam, locals are illprepared to withstand extreme sea level inundation (Anh et al., 2017; Larson et al., 2014; Takagi et al., 2012; Kleinen 2007). The prospect of higher and more frequent storm surges to the southern region by the middle of the century is therefore concerning. Highest storm surge levels $(\geq 2.5 \mathrm{~m}$ in $1 \%$ AEP, $\geq 3.5 \mathrm{~m}$ in $0.1 \%$ AEP: approximately the $95^{\text {th }}$ percentile of storm surge levels) - currently only seen along the coastline of southern China - are projected to reach into regions of north and south Vietnam over the next 30 years, more than doubling the length of coastline currently impacted (Fig. 7). Tides intensify the future storm surge hazard in these regions. Delta communities would be exposed to new storm surge hazards at precisely the time when they may be confronting increased coastal flooding from mean climate-induced sea-level rise and subsidence.

As one of the most strategically important areas of the entire model domain, we briefly explore the potential impacts of predicted extreme total sea levels to the Mekong River delta region. In a basic bath-tub analysis, we projected the extreme total sea levels (i.e. tide + surge) to a 200-km length of coastline enveloping all east-facing 
outlets of the Mekong River. In the present day 1\% AEP scenario (total extreme sea levels of 1.8-2.3 m), we found that sea dykes would moderately well protect against storm surge flooding assuming their materials can withstand surge forces. A more extreme $0.1 \%$ AEP baseline storm tide in the Mekong delta region (total extreme sea levels of 2.5-3.4 m), would however inundate the majority extent of the lower delta. Compared to this, the future 1\% AEP storm tide (projected total extreme sea level of 2.1-2.8 m), would be of sufficient height to spread inland by around $110 \mathrm{~km}$, and pose a substantial potential risk to inhabitants of the delta. Based on this basic preliminary assessment, we are currently undertaking a more rigorous examination of the potential extent of flood inundation to the Mekong River delta from extreme sea levels forced by storm surge.

It is important to note that current flood management in the Mekong delta region largely discount the risks posed by current and future storm surges, as such events are considered unlikely (Anh et al., 2017; Takagi et al., 2012). The socio-economic importance of the delta is apparent in the current network of flood defences, but along the coast these appear to be intended to protect against coastal flooding and wave action, rather than storm surges linked to TCs. The results of our study, which highlights the large - and growing - impacts of storm surge flooding even at the $1 \%$ AEP scenario level, clearly demand an urgent re-evaluation of existing flood risk assessments and guidance for the Mekong delta to include appropriate focus on the risks posed by storm surges.

Our results also show what happens to storm surge and extreme sea level frequency when TCs occur more often, with greater intensity and with broader spatial distribution by the year 2050 . What we experience as extreme storm surges today, will in the future occur with greater regularity. A storm surge occurring with $1 \%$ AEP frequency at Ho Chi Minh City today, is projected to occur at close to 2.8\% AEP (1:35 year) frequency by 2050. This is excluding the added effects of mean sea-level rise, which has an additional amplifying effect on extreme sea levels. This substantial increase in frequency suggests that flood defence standards will need to be upgraded at coastal locations and flood managers will need to consider augmented, alternative or combined methodologies to cope with more widespread, stronger or more frequent storm surge scenarios. Complex and higher dyke systems alone may be insufficient for this type of flood hazard, but it's also worthwhile considering that storm surges may combine with pluvial runoff or fluvial flooding after a typhoon or monsoonal rainfall when normal releases (e.g. drains, flood gates or flood storage areas) could be unavailable.

A shifting distribution of TCs by the year 2050 means that storm surges will be striking the coastlines further south than the baseline years, making South Vietnam, Cambodia and particularly Thailand more vulnerable to storm surge levels. Currently, $1 \%$ AEP storm surges rarely exceed $0.5 \mathrm{~m}$ in these locations. We found that higher probability storm surges (10\% AEP) along this coastline average around $0.36 \mathrm{~m}$ along this Vietnam-Cambodia-

535 Thailand portion of coastline over the next 30 years, but the lower probability, more extreme storm surges $(1 \%$ AEP to $0.1 \% \mathrm{AEP}$ ) are projected to be greater in magnitude and more frequent than they are today (Fig. 7). The most vulnerable sections of coastline here see $1 \%$ AEP storm surge heights increase by $0.6 \mathrm{~m}(0.8 \mathrm{~m}$ for $0.1 \%$ AEP surges). We again emphasise that this growth in extreme storm surge heights over time is from a previously near-zero bar: therefore flood-risk assessments for coastlines that have not previously been subjected to storm surges may no longer be fit for purpose.

Mean sea-level rise has not been explicitly incorporated in our future model simulations. We instead simply added a standard $0.25 \mathrm{~m}$ increase on top of total sea levels, for illustration purposes. Higher sea levels could act to slightly dampen surge heights, but even some additional height of water on top of storm tide levels in the final 
trade-off may be sufficient to extend inundation area or overtop carefully designed flood defences. Relative and regional sea-level rise should therefore always be considered in coastal flood emergency strategies. It is worthwhile noting that the projected increases in storm surge heights along the entire Vietnamese coastline over the next 30 years, ranges up to $0.7 \mathrm{~m}$ in the $1 \%$ AEP (and up to $1 \mathrm{~m}$ in the more extreme $0.1 \%$ AEP), but an average of either of these local OCP values actually exceeds the anticipated permanent addition due to climate change on local sea levels. Consequently, storm surge would appear to present a bigger, albeit limited-time, hazard to this region than rising mean sea levels, by 2050. This is particularly interesting, as past changes in mean sealevel have dominated changes in extreme sea levels in extra-tropical regions, with mostly negligible changes observed in storm surges (Mawdsley and Haigh 2016; Marcos et al., 2015; Seneviratne et al., 2012).

There are other factors that influence storm surge levels such as run up and set up, TC latitude or seasonality of mean sea level that are currently outside the scope of this study, but could easily be incorporated in future analysis. Naturally, there are also alternative choices that could have been made in our study approach that would or may have altered our findings. For example, we selected a single future STORM scenario (CNRM-CM6-1) out of a possible four climate model outputs and any biases in this data would also translate into our model results. However, all STORM versions of the averaged 2015-2050 future climate (Table 3) consistently showed an increase in TC intensity, frequency and altered spatial distribution in the South China Sea region. Future work could compare results across the other three simulations to better quantify uncertainty. Furthermore, the CNRMCM6-1 version was selected as a middle-road option of the four scenarios, but all the STORM future options were based on a SSP5-8.5 projected climate outcome as defined by the IPCC (IPCC, 2019). This is a limitation of our study as this presents results for a projected future climate with the highest greenhouse gas emissions between 2015-2050, assuming only limited climate change mitigation measures globally over the next 30 years, and appears to overestimate current greenhouse gas trajectories (e.g., Hausfather and Peters, 2020).

Our technique of constructing TCs for the MIKE 21 model by using the Single Vortex Holland option to define wind and pressure fields, uses a B parameter (Harper and Holland, 1999) not utilised in other methods. Therefore, alternative approaches may produce slightly different TC wind and pressure gradients in the model to induce storm surge heights. A benefit of the global climate models used in future STORM is that they run with a high spatial resolution, ideal for resolving individual TCs, but requires a trade off against computational costs so that only the period up to 2050 could be modelled (Bloemendaal et al., in review). Should this detail change and future STORM simulations are extended out to 2100 , it would be interesting to rerun the hydrodynamic model simulations for this longer time period.

\section{Conclusions}

Until recently, little was known about future changes to storm surge characteristics in the sparsely gauged regions of the world, particularly in regions exposed to tropical cyclones (TC). Statistical and numerical models have improved our knowledge in this subject area regionally and globally. However, in tropical regions where TCs are most actively creating storm surges, such as the South China Sea, coarse hydro-meteorological data and scarce tide gauge observations often limit progress. To address this problem, we utilised two newly available databases, 
each of 10,000 years of synthetic TC track data, created by Bloemendaal et al., (2020; in review). The STORM databases cover both a past period and the SSP5-8.5 future realisations to the year 2050 .

We created a bespoke hydrodynamic model of the South China Sea region to simulate 10,000 years of TC activity on sea level, for present (baseline) and projected future SSP5-8.5 climate conditions. We estimated the projected impact of TCs on storm surge heights alone, and also on extreme total sea levels (surge + tide). The model results show that probability extreme sea levels powered by storm surges will increase substantially in the near future for many sections of coastline. Today's extreme sea levels will be a more common occurrence by 2050 ; a $1 \%$ AEP (1:100 year) storm surge today, for example, will likely be experienced with a frequency closer to 5\% AEP (1:20 year) by the middle of this century. And as future TC activity increases and expands geographically, so does the spatial extent of extreme sea levels forced by storm surges. We predict that the coastlines of China and North and South Vietnam will experience a greater increase in storm surge heights than elsewhere in the domain. In a $1 \%$ AEP (1:100 year) event, levels could increase up to $0.8 \mathrm{~m}$ over present day values. We found that the length of coastline experiencing today's highest $\left(95^{\text {th }}\right.$ percentile) storm surge levels of $\geq 2.5 \mathrm{~m}$ ( $1 \%$ AEP) or $\geq 3.5 \mathrm{~m}(0.1 \%$ AEP) more than doubles over the next 30 years. But in contrast, the coastline of central Vietnam has more natural resilience against present and future storm surges because the adjacent narrow continental shelf limits surge growth even with stronger forcing.

In the present climate, the coastlines of Thailand and Cambodia hardly ever experience significant tropical cyclone storm surges. However, these countries are projected to experience changes to storm surge with higher category TCs striking sections of their coastlines over the course of the $21^{\text {st }}$ century. Our simulations predict that, for the first time, these coastlines will experience storm surge levels above $0.5 \mathrm{~m}$ in the extreme RPLs ( $\geq 1 \%$ AEP). Flood management approaches along these regional coastlines will therefore need to be reviewed for their effectiveness against future extreme sea levels and storm surges.

Our results also show that the difference between extreme storm surge heights today and those up to 2050, along the coastlines of Vietnam and its neighbours, regularly exceeds the $0.25 \mathrm{~m}$ SSP5-8.5 scenario mean sea-level rises projected for this region. Climate-driven changes in storm activity in this tropical zone will produce higher extreme sea levels, and enhance storm surge hazard, that in many locations will present a greater challenge for coastal flood management over the next decades than will sea-level rise alone.

\section{Author contribution}

MW carried out the hydrodynamic modelling simulations, formal analysis and prepared the first draft of the manuscript. IDH, SED and RJN conceptualised this work, designed the methodology and provided supervision in the UK. IDH further supervised model design and visualization. The supervision, methodology development and resources in Vietnam were provided by TBH and NNH, with formal data analysis carried out by QQL. NB provided key tropical cyclone resources for this study. All authors commented and edited the manuscript prior to submission. 
https://doi.org/10.5194/nhess-2021-397

Preprint. Discussion started: 17 January 2022

(C) Author(s) 2022. CC BY 4.0 License.

\section{Competing interests}

615 The authors declare that they have no conflict of interest.

\section{Acknowledgements}

This work was supported by the Natural Environment Research Council, in the UK (Grant Number NE/S003150/1). Also supported in Vietnam by the Ministry of Science and Technology of Vietnam and the National Foundation of Science and Technology Development (NAFOSTED-RCUK fund). The authors also wish

620 to acknowledge the use of the IRIDIS High Performance Computing Facility, and associated support services at the University of Southampton, in the completion of this work. Lastly, this work could also not have been completed without access to the STORM present and future datasets (Bloemendaal et al., in review). NB is funded by a VICI grant from the Netherlands Organization for Scientific Research 569 (NWO Grant Number 453-13006) and the ERC Advanced Grant (Grant Number COASTMOVE 884442). 


\section{References}

Anh, L.T., Takagi, H., Thao, N.D. and Esteban, M., Investigation of awareness of typhoon and storm surge in the Mekong Delta-Recollection of 1997 Typhoon Linda, Journal of Japan Society of Civil Engineers, Ser.B3 (Ocean Engineering). Vol. 73(2), pp.I_168-I_173, 2017.

Arns, A., Wahl, T., Wolff, C. et al., Non-linear interaction modulates global extreme sea levels, coastal flood exposure, and impacts, Nat Commun. 11, 1918, https://doi.org/10.1038/s41467-020-15752-5, 2020.

Bangalore, M., Smith, A. and Veldkamp, T., Exposure to floods, climate change, and poverty in Vietnam, Economics of Disasters and Climate Change volume 3, p79-99, https://doi.org/10.1007/s41885-018-0035-4, The World Bank, 2019.

Baranes, H.E., Woodruff, J.D., Talke, S.A., Kopp, R.E., Ray, R.D. and DeConto, R.M., Tidally driven interannual variation in extreme sea level frequencies in the Gulf of Maine, Journal of Geophysical Research: Oceans, 125(10), p.e2020JC016291, 2020.

Bloemendaal, N.; Haigh, I.D., de Moel, H. ; Muis, S, Haarsma, R.J., Aerts, J.C.J.H., STORM IBTrACS present climate synthetic tropical cyclone tracks, 4TU. Research Data, Dataset. https://doi.org/10.4121/12706085.v3, 2019a.

Bloemendaal, N., Muis, S., Haarsma, R.J., Verlaan, M., Apecechea, M.I., de Moel, H., Ward, P.J. and Aerts, J.C., Global modeling of tropical cyclone storm surges using high-resolution forecasts, Climate Dynamics, 52(7), pp.5031-5044, 2019b.

Bloemendaal, N., Haigh, I.D., de Moel, H., Muis, S., Haarsma, R.J. and Aerts, J.C., Generation of a global synthetic tropical cyclone hazard dataset using STORM, Scientific Data, 7(1), pp.1-12, 2020.

Bloemendaal, N., de Moel H., Martinez A.B., Muis, S., Haigh, I.D., van der Wiel K., Haarsma, R.J., Ward P., Roberts M.J., Dullaart J.C.M. and Aerts, J.C.J.H., A globally consistent local-scale assessment of future tropical cyclone risk. Submitted to Science Advances.

Caldwell, P. C., Merrifield, M. A. Thompson, P. R., Sea level measured by tide gauges from global oceans - the Joint Archive for Sea Level holdings (NCEI Accession 0019568), Version 5.5, NOAA National Centers for Environmental Information, Dataset, doi:10.7289/V5V40S7W, 2015.

Chan, J.C., Interannual and interdecadal variations of tropical cyclone activity over the western North Pacific, Meteorology and Atmospheric Physics, 89(1), pp.143-152, 2005.

Cid, A., Camus, P., Castanedo, S., Mendez, F., \& Medina, R., Global reconstructed daily surge levels from the 20th Century Reanalysis (1871-2010), Global and Planetary Change, 148, 9-21, 2017.

Cid, A., Wahl, T., Chambers, D., \& Muis, S., Storm Surge Reconstruction and Return Water Level Estimation in Southeast Asia for the 20th Century, Journal of Geophysical Research, 123(1), 437-451, 2018.

C3S (Copernicus Climate Change Service), ERA5: Fifth Generation of ECMWF Atmospheric Reanalyses of the Global Climate, https://cds.climate.copernicus.eu/, 2020.

Dang, T.D., Cochrane, T.A. and Arias, M.E., Future hydrological alterations in the Mekong Delta under the impact of water resources development, land subsidence and sea-level rise, Journal of Hydrology: Regional Studies, 15, pp.119-133, 2018.

Dasgupta, S., Laplante, B., Meisner, C., Wheeler, D. and Yan, J., The impact of sea-level rise on developing countries: a comparative analysis, Climatic change, 93(3), pp.379-388, 2009.

DHI. MIKE 21 Flow Model - Hydrodynamic Module, User Guide, https://manuals.mikepoweredbydhi.help/latest/Coast_and_Sea/M21HD.pdf, 2017a. 
DHI. MIKE 21 Flow Model - Cyclone Wind Generation Tool. Scientific Documentation, https://manuals.mikepoweredbydhi.help/2017/Coast_and_Sea/CycloneTool_Scientific_Doc.pdf, Last access: January 2020. 2017b.

Dullaart, J.C., Muis, S., Bloemendaal, N., Chertova, M.V., Couasnon, A. and Aerts, J.C., Accounting for tropical cyclones more than doubles the global population exposed to low-probability coastal flooding, Communications Earth \& Environment, 2(1), pp.1-11, 2021.

Edmonds, D.A., Caldwell, R.L., Brondizio, E.S. and Siani, S.M., Coastal flooding will disproportionately impact people on river deltas, Nature communications, 11(1), pp.1-8, 2020

Emanuel, K.A. Downscaling CMIP5 climate models shows increased tropical cyclone activity over the 21st century, Proceedings of the National Academy of Sciences, 110(30), pp.12219-12224, 2013.

Emanuel, K., Response of global tropical cyclone activity to increasing CO2: Results from downscaling CMIP6 models, Journal of Climate, 34(1), pp.57-70, 2021.

Erban, L.E., Gorelick, S.M. and Zebker, H.A., Groundwater extraction, land subsidence, and sea-level rise in the Mekong Delta, Vietnam, Environmental Research Letters, 9(8), p.084010, 2014.

Fox-Kemper, B., H. T. Hewitt, C. Xiao, G. Aðalgeirsdóttir, S. S. Drijfhout, T. L. Edwards, N. R. Golledge, M. Hemer, R. E. Kopp, G. Krinner, A. Mix, D. Notz, S. Nowicki, I. S. Nurhati, L. Ruiz, J-B. Sallée, A. B. A. Slangen, Y. Yu, Ocean, Cryosphere and Sea Level Change. In: Climate Change 2021: The Physical Science Basis. Contribution of Working Group I to the Sixth Assessment Report of the Intergovernmental Panel on Climate Change [Masson-Delmotte, V., P. Zhai, A. Pirani, S. L. Connors, C. Péan, S. Berger, N. Caud, Y. Chen, L. Goldfarb, M. I. Gomis, M. Huang, K. Leitzell, E. Lonnoy, J. B. R. Matthews, T. K. Maycock, T. Waterfield, O. Yelekçi, R. Yu and B. Zhou (eds.)]. Cambridge University Press, In Press, 2021.

Fritz, H.M., Blount, C.D., Thwin, S., Thu, M.K. and Chan, N., Cyclone Nargis storm surge in Myanmar, Nature Geoscience, 2(7), pp.448-449, 2009.

Guo, S.L., A discussion on unbiased plotting positions for the general extreme value distribution, Journal of Hydrology, 121(1-4), pp.33-44, 1990.

GFDRR, Country Profile: Vietnam. https://www.gfdrr.org/en/publication/country-profile-vietnam, Last access: 12 December 2020, 2015.

Haigh, I.D., Eliot, M. and Pattiaratchi, C., Global influences of the 18.61 year nodal cycle and 8.85 year cycle of lunar perigee on high tidal levels, Journal of Geophysical Research: Oceans, 116(C6), 2011.

Haigh, I.D., MacPherson, L.R., Mason, M.S., Wijeratne, E.M.S., Pattiaratchi, C.B., Crompton, R.P. and George, S., Estimating present day extreme sea level exceedance probabilities around the coastline of Australia: tropical cyclone-induced storm surges, Climate Dynamics, 42(1-2), pp.139-157, 2014.

Harper, B.A. and Holland, G.J., An updated parametric model of the tropical cyclone, In Proc. 23rd Conf. Hurricanes and Tropical Meteorology, January 1999. (pp. 10-15). 1999.

Hausfather, Z. and Peters, G.P., Emissions-the 'business as usual' story is misleading, Nature, 577(7792), pp.618-621, 2020.

Hersbach, H., Bell, B., Berrisford, P., Biavati, G., Horányi, A., Muñoz Sabater, J., Nicolas, J., Peubey, C., Radu, R., Rozum, I., Schepers, D., Simmons, A., Soci, C., Dee, D., Thépaut, J-N., ERA5 hourly data on single levels from 1979 to present. Copernicus Climate Change Service (C3S) Climate Data Store (CDS).

10.24381/cds.adbb2d47, 2018.

Hinkel, J., Lincke, D., Vafeidis, A.T., Perrette, M., Nicholls, R.J., Tol, R.S., Marzeion, B., Fettweis, X., Ionescu, C. and Levermann, A., Coastal flood damage and adaptation costs under 21 st century sea-level rise, Proceedings of the National Academy of Sciences, 111(9), pp.3292-3297, 2014.

Holland, G.J., An analytic model of the wind and pressure profiles in hurricanes, Monthly weather review, 108(8), pp.1212-1218, 1980. 
Horsburgh, K. J. \& Wilson, C., Tide-surge interaction and its role in the distribution of surge residuals in the North Sea. J. Geophys, Res. 112, C08003, 2007.

Hung, N.N., Delgado, J.M., Tri, V.K., Hung, L.M., Merz, B., Bárdossy, A. and Apel, H., Floodplain hydrology of the Mekong delta, Vietnam, Hydrological Processes, 26(5), pp.674-686, 2012.

Idier, D., Bertin, X., Thompson, P. and Pickering, M.D., Interactions between mean sea level, tide, surge, waves and flooding: mechanisms and contributions to sea level variations at the coast, Surveys in Geophysics, 40(6), pp.1603-1630, 2019.

Irish, J.L., Resio, D.T. and Divoky, D., Statistical properties of hurricane surge along a coast, Journal of Geophysical Research: Oceans, 116(C10), 2011.

IPCC. Climate Change and Land: an IPCC special report on climate change, desertification, land degradation, sustainable land management, food security, and greenhouse gas fluxes in terrestrial ecosystems [P.R. Shukla, J. Skea, E. Calvo Buendia, V. Masson-Delmotte, H.-O. Pörtner, D. C. Roberts, P. Zhai, R. Slade, S. Connors, R. van Diemen, M. Ferrat, E. Haughey, S. Luz, S. Neogi, M. Pathak, J. Petzold, J. Portugal Pereira, P. Vyas, E. Huntley, K. Kissick, M.Belkacemi, J. Malley, (eds.)], In press, 2019.

Jelesnianski, C.P., SPLASH : (Special Program to List Amplitudes of Surges from Hurricanes), I, Landfall storms, United States, National Weather Service., Techniques Development Laboratory, NOAA technical memorandum NWS TDL; 46, https://repository.library.noaa.gov/view/noaa/13509, 1972.

Kirezci, E., Young, I.R., Ranasinghe, R., Muis, S., Nicholls, R.J., Lincke, D. and Hinkel, J., Projections of global-scale extreme sea levels and resulting episodic coastal flooding over the 21 st Century, Scientific reports, 10(1), pp.1-12, 2020.

Kleinen, J., Historical perspectives on typhoons and tropical storms in the natural and socio-economic system of Nam Dinh (Vietnam), Journal of Asian Earth Sciences, 29(4), pp.523-531, 2007.

Knabb, R.D., Rhome, R.R and Brown, D.P. Tropical Cyclone Report hurricane Katrina, 23 -30 August 2005. National Hurricane Center, https://www.nhc.noaa.gov/data/tcr/AL122005_Katrina.pdf. Last access: 15 December 2021, 2011.

Knapp, K. R., M. C. Kruk, D. H. Levinson, H. J. Diamond, and C. J. Neumann, The International Best Track Archive for Climate Stewardship (IBTrACS): Unifying tropical cyclone best track data. Bulletin of the American Meteorological Society, 91, 363-376, non-government domain doi:10.1175/2009BAMS2755.1, 2010.

Knutson, T., Camargo, S.J., Chan, J.C., Emanuel, K., Ho, C.H., Kossin, J., Mohapatra, M., Satoh, M., Sugi, M., Walsh, K. and Wu, L., Tropical cyclones and climate change assessment: Part II: Projected response to anthropogenic warming, Bulletin of the American Meteorological Society, 101(3), pp.E303-E322,

Lagmay, Alfredo Mahar Francisco, Rojelee P. Agaton, Mark Allen C. Bahala, Jo Brianne Louise T. Briones, Krichi May C. Cabacaba, Carl Vincent C. Caro, Lea L. Dasallas et al. , Devastating storm surges of Typhoon Haiyan, International journal of disaster risk reduction 11, pp1-12, 2015.

Kossin, J.P., Emanuel, K.A. and Vecchi, G.A., The poleward migration of the location of tropical cyclone maximum intensity, Nature, 509(7500), pp.349-352, 2014.

Lap, T.Q., Researching the variation of typhoon Intensities under climate change in Vietnam: A case study of typhoon Lekima, 2007, Hydrology, 6(2), p.51, 2019.

Larson, M., Hung, N.M., Hanson, H., Sundström, A. and Södervall, E., Impacts of Typhoons on the Vietnamese Coastline: A Case Study of Hai Hau Beach and Ly Hoa Beach, In Coastal Disasters and Climate Change in Vietnam (pp. 17-42), Elsevier, 2014.

Marcos, M., Calafat, F.M., Berihuete, Á. and Dangendorf, S., Long-term variations in global sea level extremes, Journal of Geophysical Research: Oceans, 120, 8115-8134, doi: 10.1002/2015JC011173, 2015. 
Martin, P.J., Smith, S.R., Posey, P.G., Dawson, G.M. and Riedlinger, S.H., Use of the Oregon State University tidal inversion software (OTIS) to generate improved tidal prediction in the East-Asian Seas, Naval Research Lab Stennis Space Center MS Oceanography Div., 2009.

Mawdsley R.J. and Haigh I.D., Spatial and temporal variability and long-term trends in skew surges globally, Frontiers in Marine Science, 3:29, https://doi.org/10.3389/fmars.2016.00029, 2016.

McGranahan, G., Balk, D. and Anderson, B., The rising tide: assessing the risks of climate change and human settlements in low elevation coastal zones, Environment and urbanization, 19(1), pp.17-37, 2007.

Minderhoud, P.S.J., Erkens, G., Pham, V.H., Bui, V.T., Erban, L., Kooi, H. and Stouthamer, E., Impacts of 25 years of groundwater extraction on subsidence in the Mekong delta, Vietnam, Environmental research letters, 12(6), p.064006, 2017.

Mousavi, M.E., Irish, J.L., Frey, A.E., Olivera, F. and Edge, B.L., Global warming and hurricanes: the potential impact of hurricane intensification and sea level rise on coastal flooding, Climatic Change, 104(3), pp.575-597, 2011.

Muis, S., Verlaan, M., Winsemius, H.C., Aerts, J.C. and Ward, P.J., A global reanalysis of storm surges and extreme sea levels, Nature communications, 7(1), pp.1-12, 2016.

Muis, S., Apecechea, M.I., Dullaart, J., de Lima Rego, J., Madsen, K.S., Su, J., Yan, K. and Verlaan, M., A High-resolution global dataset of extreme sea levels, tides, and storm surges, including future projections, Frontiers in Marine Science, 7, p.263, 2020.

Murakami, H. and Sugi, M., Effect of model resolution on tropical cyclone climate projections, Sola, 6, pp.7376, 2010.

Nicholls, R.J., Storm surges in coastal areas. In: Arnold, M., Chen, R.S., Deichmann, U., Dilley, M., LernerLam, A.L., Pullen, R.E. and Trohanis, Z. (eds.) Natural Disaster Hotspots Case Studies, The World Bank Hazard Management Unit, Disaster Risk Management Series, 6, pp.79-108, Washington, DC: World Bank, 2006.

Nicholls, R.J. and Cazenave, A., Sea-level rise and its impact on coastal zones. science, 328(5985), pp.15171520, 2010.

Nicholls, R.J., Lincke, D., Hinkel, J., Brown, S., Vafeidis, A.T., Meyssignac, B., Hanson, S.E., Merkens, J.L. and Fang, J., A global analysis of subsidence, relative sea-level change and coastal flood exposure, Nature Climate Change, pp.1-5, 2021.

Nguyen, H.N., Vu, K.T. and Nguyen, X.N., Flooding in Mekong River Delta, Viet Nam (No. HDOCPA-200753), Human Development Report Office (HDRO), United Nations Development Programme (UNDP), 2007.

Oppenheimer, M., B.C. Glavovic, J. Hinkel, R. van de Wal, A.K. Magnan, A. Abd-Elgawad, R. Cai, M. Cifuentes-Jara, R.M. DeConto, T. Ghosh, J. Hay, F. Isla, B. Marzeion, B. Meyssignac, and Z. Sebesvari, Sea Level Rise and Implications for Low-Lying Islands, Coasts and Communities. In: IPCC Special Report on the Ocean and Cryosphere in a Changing Climate [H.-O. Pörtner, D.C. Roberts, V. Masson-Delmotte, P. Zhai, M. Tignor, E. Poloczanska, K. Mintenbeck, A. Alegría, M. Nicolai, A. Okem, J. Petzold, B. Rama, N.M. Weyer (eds.)], 2019.

Pandey, S. and Rao, A.D., Impact of approach angle of an impinging cyclone on generation of storm surges and its interaction with tides and wind waves, Journal of Geophysical Research: Oceans, 124(11), pp.7643-7660, 2019.

Pasch, R.J., Penny, A.B. and Berg, R., Tropical Cyclone Report: Hurricane Maria. National Hurricane center, TC REPORT AL152017, National Oceanic And Atmospheric Administration and the National Weather Service, pp.1-48, 2018.

Pawlowicz, R., B. Beardsley, and S. Lentz, Classical Tidal Harmonic Analysis Including Error Estimates in MATLAB using T_TIDE, Computers and Geosciences, 28, 929-937, 2002 
Peng, D., Hill, E.M., Meltzner, A.J. and Switzer, A.D., Tide gauge records show that the 18.61-year nodal tidal cycle can change high water levels by up to $30 \mathrm{~cm}$, Journal of Geophysical Research: Oceans, 124(1), pp.736749, 2019.

Phan, H.M., Ye, Q., Reniers, A.J. and Stive, M.J., Tidal wave propagation along The Mekong deltaic coast, Estuarine, Coastal and Shelf Science, 220, pp.73-98, 2019.

Poulose, J., Rao, A.D. and Bhaskaran, P.K., Role of continental shelf on non-linear interaction of storm surges, tides and wind waves: An idealized study representing the west coast of India, Estuarine, Coastal and Shelf Science, 207, pp.457-470, 2018.

Pugh, D. and Woodworth, P., Sea-level science: understanding tides, surges, tsunamis and mean sea-level changes, Cambridge University Press, 2014.

Ramos-Valle, A.N., Curchitser, E.N. and Bruyère, C.L., Impact of tropical cyclone landfall angle on storm surge along the Mid-Atlantic bight, Journal of Geophysical Research: Atmospheres, 125(4), p.e2019JD031796, 2020.

Rego, J.L. and Li, C., Nonlinear terms in storm surge predictions: Effect of tide and shelf geometry with case study from Hurricane Rita, Journal of Geophysical Research: Oceans, 115(C6), 2010.

Simpson, R.H. and Saffir, H., The hurricane disaster potential scale, Weatherwise, 27(8), p.169, 1974.

Santos-Burgoa, C., Goldman, A., Andrade, E., Barrett, N., Colon-Ramos, U., Edberg, M., Garcia-Meza, A., Goldman, L., Roess, A., Sandberg, J. and Zeger, S., Ascertainment of the estimated excess mortality from hurricane Maria in Puerto Rico, Himmelfarb Health Sciences Library, The George Washington University, Health Sciences Research Commons, Global Health Faculty Publications, Retrieved from https://hsrc.himmelfarb.gwu.edu/sphhs_global_facpubs/288, 2018.

Seneviratne, S.I., Nicholls, N., Easterling, D., Goodess, C., Kanae, S., Kossin, J., Luo, Y., Marengo, J., McInnes, K., Rahimi, M. and Reichstein, M., Managing the risks of extreme events and disasters to advance climate change adaptation, A special report of working Groups I and II of the Intergovernmental Panel on Climate Change (IPCC), 2012.

SwissRe, Industry-first Global Storm Surge Zones, https://www.swissre.com/dam/jcr:dedf399f-af17-4061-928fdba8229c1499/industry_first_global_storm_surge_zones.pdf, Last access: 25 January 2021, 2017.

Tadesse, M.G. and Wahl, T., A database of global storm surge reconstructions, Scientific Data, 8(1), pp.1-10, 2021.

Takagi, H., Thao, N.D., Esteban, M., Tran, T.T., Knaepen, H.L., Mikami, T. Vulnerability of coastal areas in southern Vietnam against tropical cyclones and storm surges, In Proceedings of the 4th International Conference on Estuaries and Coasts (ICEC), Hanoi, Vietnam, 8-11 October 2012, pp. 292-299. 2012.

Takagi, H., Esteban, M., Shibayama, T., Mikami, T., Matsumaru, R., De Leon, M., Thao, N.D., Oyama, T. and Nakamura, R., Track analysis, simulation, and field survey of the 2013 Typhoon Haiyan storm surge, Journal of Flood Risk Management, 10(1), pp.42-52, 2017.

Tozer, B., Sandwell, D.T., Smith, W.H.F., Olson, C., Beale, J.R. and Wessel, P., Global bathymetry and topography at 15 arc sec: SRTM15+. Earth and Space Science, 6(10), pp.1847-1864, 2019.

OCHA (UN Office for the Coordination of Humanitarian Affairs), Typhoon Bopha Situation Report No. 19. https://reliefweb.int/report/philippines/typhoon-bopha-situation-report-no-19-12-february-2013. Last access: 25 January 2021, 2013.

Voldoire, A., Sanchez-Gomez, E., y Mélia, D.S., Decharme, B., Cassou, C., Sénési, S., Valcke, S., Beau, I., Alias, A., Chevallier, M. and Déqué, M., The CNRM-CM5. 1 global climate model: description and basic evaluation, Climate dynamics, 40(9), pp.2091-2121, 2013.

Vousdoukas, M.I., Voukouvalas, E., Annunziato, A., Giardino, A. and Feyen, L., Projections of extreme storm surge levels along Europe, Climate Dynamics, 47(9), pp.3171-3190, 2016. 
Wahl, T. and Chambers, D.P., Climate controls multidecadal variability in US extreme sea level records, Journal of Geophysical Research: Oceans, 121(2), pp.1274-1290, 2016.

Wahl, T., Haigh, I.D., Nicholls, R.J., Arns, A., Dangendorf, S., Hinkel, J. and Slangen, A.B., Understanding extreme sea levels for broad-scale coastal impact and adaptation analysis, Nature communications, 8(1), pp.1$12,2017$.

Williams, J., Horsburgh, K.J., Williams, J. A. \& Proctor, R.N.F., Tide and skew surge independence: new insights for flood risk, Geophys. Res. Lett., https://doi.org/10.1002/2016GL069522, 2016.

WMO (World Meteorological Organization), Storm Surge, https://public.wmo.int/en/our-mandate/focusareas/natural-hazards-and-disaster-risk-reduction/storm-surge, Last access: 21 January 2021, 2021.

Woodruff, J.D., Irish, J.L. and Camargo, S.J., Coastal flooding by tropical cyclones and sea-level rise, Nature, 504(7478), pp.44-52, 2013.

Wong, P.P., I.J. Losada, J.-P. Gattuso, J. Hinkel, A. Khattabi, K.L. McInnes, Y. Saito, and A. Sallenger, Coastal systems and low-lying areas. In: Climate Change 2014: Impacts, Adaptation, and Vulnerability. Part A:Global and Sectoral Aspects. Contribution of Working Group II to the Fifth Assessment Report of the Intergovernmental Panel on Climate Change [Field, C.B., V.R. Barros, D.J. Dokken, K.J. Mach,M.D. Mastrandrea, T.E. Bilir, M. Chatterjee, K.L. Ebi, Y.O. Estrada, R.C. Genova, B. Girma, E.S. Kissel, A.N. Levy,S. MacCracken, P.R. Mastrandrea, and L.L. White (eds.)], Cambridge University Press, Cambridge, United Kingdom and New York, NY, USA, pp. 361-409, 2014.

Zhang, B. and Wang, S., Probabilistic characterization of extreme storm surges induced by tropical cyclones, Journal of Geophysical Research: Atmospheres, 126(3), p.e2020JD033557, 2021. 


\section{Appendix A}

\section{A.1 Hydrodynamic model sensitivity tests}

We undertook sensitivity tests to assess whether it was necessary to include the astronomical tide when simulating sea level conditions for each cyclone. Simulating tides adds the complexity that each cyclone must be randomly assigned a specific day and start time, but STORM only assigns each cyclone to a month. Customarily extreme sea level modelling studies simulate storm surges separately from the tides and then statistically combine the two to estimate total sea level return periods (e.g. Dullaart et al., 2021). However, this approach ignores the fact that non-linear interactions between the tide and non-tidal components of sea level have been reported for many places around the world and typically result in the highest observed non-tidal residuals occurring around mid-tide or lowtide rather than at the time of tidal high water (e.g. Idier et al., 2019; Poulose et al., 2018; Mawdsley and Haigh, 2016; Williams et al., 2016; Rego and Li 2010; Horsburgh and Wilson, 2007). Arns et al. (2020) have recently shown that flood risk can be underestimated if these non-linear interactions are not accounted for, as Haigh et al. (2014) discovered with storm surge errors exceeding $1 \mathrm{~m}$ along the Australian coastline, when surges were simulated independently of tide for Category 5 Tropical Cyclone Rosita (2000).

In our approach to assess the significance of non-linear interactions in this region, the first step was to create model results with meteorological forcing only. We recreated Typhoon Ketsana (2009) using data from the IBTrACS database, and the MIKE 21 FM Cyclone Wind Generation tool (DHI, 2017b) with Holland B parameter estimated using the Holland Formula (Harper and Holland, 1999). Then, four comparative model runs were undertaken in which the model was driven with both tidal and meteorological forcing. In these four comparative simulations we shifted the timing of the meteorological forcing so that the peak of the surge occurred: (1) around the time of low tide; (2) on the rising tide; (3) at high tide; and (4) on the ebb tide. The results are shown in Fig. A1 and highlight that differences in the height and timing of the simulated surge between tidal and meteorological forcing versus meteorological forcing alone, around the mid-section of Vietnam, are nominal. Whilst the maximum height and duration of the event is not affected, the shape and timing of the surge peak is impacted by as much as $0.25 \mathrm{~m} / 6 \mathrm{hrs}$ between high and low tidal states. This influence should be acknowledged. But because this difference is small relative to the Vietnam tidal range, for simplicity in our study we implemented all hydrodynamic model simulations as meteorological forcing only ('surge-only') with the intension that results may afterwards be added to a randomly selected maximum tide to compute total sea levels and associated return periods. 
https://doi.org/10.5194/nhess-2021-397

Preprint. Discussion started: 17 January 2022

(C) Author(s) 2022. CC BY 4.0 License.
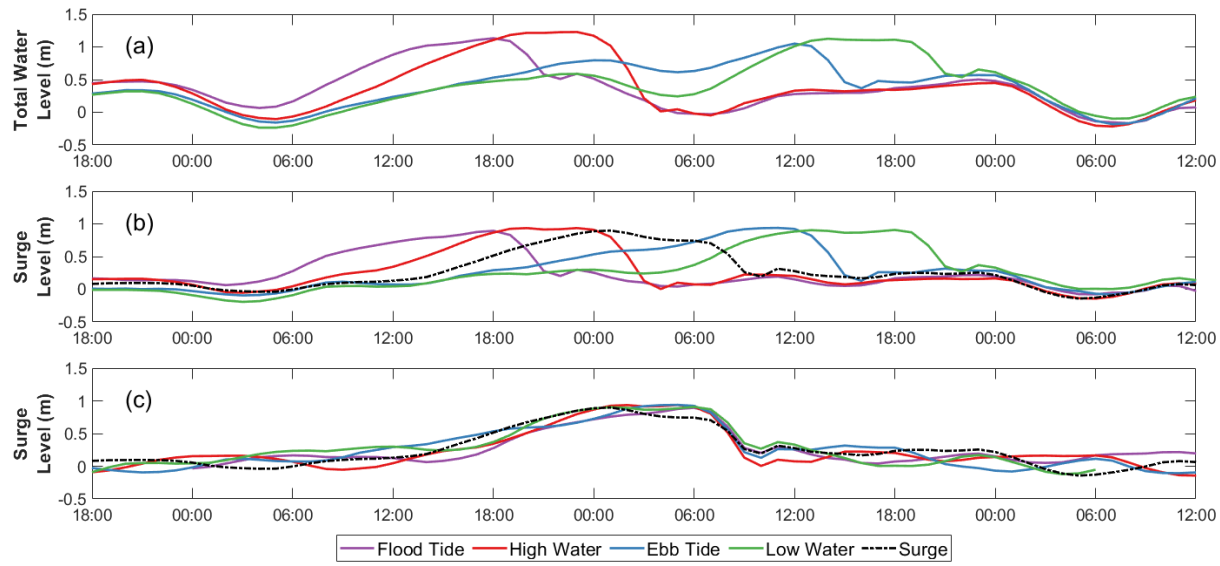

Figure Al - Tide-surge interaction for the Saffir Simpson scale category 2 Typhoon Ketsana at Son Tra, Vietnam (11 in Fig. 1) which made landfall on 29 September 2009: (a) total sea levels for low to high tide states; (b) tide states surge-only levels and (c) tide states surge-only levels adjusted for time offset from peak. 